\title{
STUDIES ON THE HEAT RESISTANCE OF TIGRIOPUS JAPONICUS
}

$\operatorname{AUTHOR}(\mathrm{S})$ :

Matutani, Kozi

CITATION:

Matutani, Kozi. STUDIES ON THE HEAT RESISTANCE OF TIGRIOPUS JAPONICUS. PUBLICATIONS OF THE SETO MARINE BIOLOGICAL LABORATORY 1961, 9(2): 379-411

\section{ISSUE DATE:}

1961-12-20

URL:

http://hdl.handle.net/2433/175285

RIGHT: 


\title{
STUDIES ON THE HEAT RESISTANCE OF TIGRIOPUS JAPONICUS ${ }^{1)}$
}

\author{
KôzI MATUTANI \\ Department of Biology, Faculty of Science, Osaka City University
}

With Plates XVI-XVII and 16 Text-figures

The copepod, Tigriopus japonicus MORI, is a microscopical marine organism which inhabits small pools on rocks exposed above the sea. Since its habitat is situated well above the high tide mark, this species is always subjected to rapid and drastic changes of environmental conditions. Such pools with limited quantities of water are very susceptible to the daily and annual fluctuations of solar radiation and air temperature. Water temperature may rise above $40^{\circ}$ in summer and fall down toward $0^{\circ} \mathrm{C}$ in winter. Salinity is liable to be changed steeply by concentration due to evaporation and by dilution with rain water. Oxygen concentration may also vary considerably because of the smallness of water volume in comparison to the abundance of organisms.

Such being the habitat, Trigriopus is expected to possess a high degree of capacity to adapt itself in response to changes in the environment. TAkedA (1954), studying the temperature acclimatization in this species, found that its heat tolerance was affected markedly by its thermal history. This noteworthy study was discontinued by his regrettable death. The present writer was much interested in the findings of TAKEDA and has undertaken the present investigation to trace his experiments and further to analyse the mechanism underlying the temperature acclimatization of this species.

The phenomenon of temperature acclimatization in poikilotherms has long attracted the attention of many biologists and it has become of recent years an increasingly fascinating object of inquiry in the field of animal physiology and ecology. There is an enormous mass of information available on this phenomenon (e.g., Loeb and Wasteneys 1912, Brett 1944, 1946, Doudoroff 1942, 1946), which was summarized and reviewed by some authors, such as PRECHT (1958) and

1) Contributions from the Laboratory of Animal Physiology, Osaka City University, No. 64.

Contributions from the Adaptive Variation Research Group, No. 53.

Contributions from the Seto Marine Biological Laboratory, No. 375.

Publ. Seto Mar. Biol. Lab., IX (2), 1961. (Article 21) 
Fisher (1958). As for the mechanism by which temperature acclimatization is effected, however, still there is a disagreements among opinions and the problem has not yet been settled.

The effect of ambient temperature is no doubt more direct on the protoplasm of every part of the body in poikilotherms than in homoiotherms. Thus, one of the orthodox ways to approach this problem is to push the analysis further down the levels of organization, namely, from the individual level to the organ, tissue and cellular levels. This direction of analysis has lately been growing in popularity. Another important way of approach is to keep under various conditions large numbers of animals, which are relatively small in size and easy to culture in the laboratory, and to observe precisely the influences of these conditions on the process of temperature acclimatization. Based on the results obtained, the mechanism of acclimatization is to be inferred. Tigriopus is certainly one of the most suitable experimental materials for the latter way of approach. In addition, the results of experiments with this material will perhaps be very interesting from the ecological point of view when they are considered in comparison to the peculiarities of its natural environment.

The present paper deals mainly with the processes of loss and gain of heat resistance in Tigriopus acclimated to different temperatures. The experimental results were partly published (Matutani $1960 \mathrm{a}, \mathrm{b}$ ).

\section{Materials and Culture Method}

Experimental materials were all obtained from our laboratory stock cultures of Tigriopus japonicus MORI, which had originated from masses of individuals collected from the small pools near the Seto Marine Biological Laboratory, Sirahama, Wakayama Prefecture (Plate XVI) and had been maintained in our laboratory for at least 5 generations at $19^{\circ}-20^{\circ} \mathrm{C}$. Tigriopus, from hatching to maturity, passes through eleven stages which are divided into six nauplius stages and five copepodid stages. The 5 th copepodid stage is followed by the adult stage. The distinction between sexes, which is very clear in the adult stage, appears first in the 4th copepodid stage (TAKEDA 1939).

The stock lines were cultured under fluorescent tubes in natural sea water which was carried from the Seto Marine Biological Laboratory. They received as food the marine alga, Plectonema terebrans, cultured in the laboratory and, in small amounts, powdered dry shrimp.

All the experiments were made with adult animals, $0.81-0.88 \mathrm{~mm}$ in body length, sampled at random from the stock cultures (Plate XVII 3 and 4). When they were exposed to a high lethal temperature, they became immobile at last bending upward their abdomens (Plate XVII 5 and 6). These individuals never recovered if returned to the normal temperature. Hence this response was adopted as the criterion of death for discriminating the dead from the alive in the experiments. 


\section{Experiment 1.}

\section{Change of heat resistance according to acclimation temperature in animals reared at $20^{\circ} \mathrm{C}$}

To begin with, the mode of change of heat resistance was investigated in animals which were transferred from a rearing temperature of $20^{\circ} \mathrm{C}$ to four different acclimation temperatures.

\section{Materials and methods}

From the stock of Tigriopus japonicus MORI which had been maintained in the laboratory for about 4 years after collection from Sirahama, adult animals were gathered and reared at $20^{\circ} \mathrm{C}$ (rearing temperature) for 45 days in glass

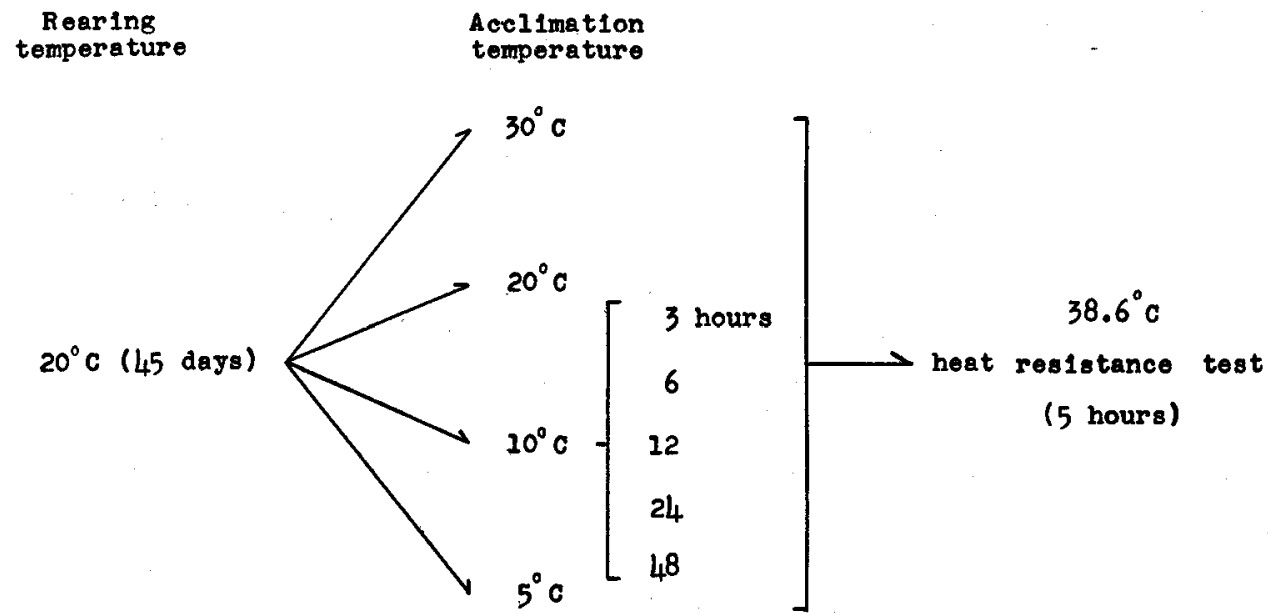

Fig. 1. Procedure of experiment 1 .

cylinders, $93 \mathrm{~mm}$ in diameter by $50 \mathrm{~mm}$ high, containing $170 \mathrm{ml}$ of sea water and placed under a $20 \mathrm{~W}$ fluorescent tube. They received the food once a day. From this $20^{\circ}$ culture, adult animals were transferred to four different acclimation temperatures of $5^{\circ}, 10^{\circ}, 20^{\circ}$ and $30^{\circ} \mathrm{C}$, at which they were maintained in hemispherical glass bowls, $55 \mathrm{~mm}$ in diameter, containing $22 \mathrm{ml}$ of sea water for definite lengths of time of $3,6,12,24$ and 48 hours before they were tested for their heat resistance (Fig. 1). They received no food in the acclimation temperatures.

The heat resistance test was conducted in the following way: Four test tubes, $15 \mathrm{~mm}$ in diameter by $160 \mathrm{~mm}$ long, containing $20 \mathrm{ml}$ of sea water were immersed fully in a water bath controlled thermostatically at $38.6^{\circ} \mathrm{C}$. After thermal equilibrium was established between the sea water in the test tubes and the water bath, about 100 individuals sampled at random from each temperature acclimation 
group were put in each test tube. The tubes were examined every hour till the 5 th hour and the numbers of surviving individuals were recorded, picking out dead individuals every time.

In this way, about 2000 individuals were used for one series of tests. The experiment was repeated 5 times, and average values were calculated from the results of these experiments.

The temperature of $38.6^{\circ} \mathrm{C}$ at which heat resistance was tested was determined by a number of preliminary experiments. TAKEDA (1954) used $38^{\circ} \mathrm{C}$ for his heat resistance test on the same species. But this temperature was too low to conduct the heat resistance test efficiently and took so long time to detect differences among the acclimation groups that there was an increasing probability that the results of test might involve some side effects, such as the secondary temperature acclimatization and microbial interference during the test. The temperature of $38.6^{\circ} \mathrm{C}$ was found most appropriate, being neither too high nor too low to evaluate efficiently as well as exactly the net effect of acclimation.

\section{Results and consideration}

The results obtained are illustrated in Fig. 2 A-E. Fig. $2 \mathrm{~A}$ gives the timesurvival curves at $38.6^{\circ} \mathrm{C}$ of animals acclimated from the same rearing temperature of $20^{\circ}$ to four different temperatures for 3 hours. In both sexes, $30^{\circ}$-acclimated animals show the greatest heat resistance. Difference in resistance is slight among $5^{\circ}-, 10^{\circ}-$ and $20^{\circ}$-acclimated animals, their per cent survival curves sometimes crossing one another.

It is within 6 hours in acclimation (Fig. 2 B) that the differences in heat resistance among the four temperature groups become distinct and consistent. These differences grow larger with the duration of time of acclimation and the heat resistance of each group appears to reach a stationary state in 12 hours, though that of $20^{\circ}$ group remains almost unchanged for 48 hours. The groups other than the $20^{\circ}$-acclimated show more or less marked gains in heat resistance. Thus they are eventually resistant to heat in the order: $30^{\circ}>5^{\circ}>10^{\circ}>20^{\circ}$ of acclimation temperature, in both sexes.

These time-survival curves are very implicative representing the extents of individual variation in heat resistance. For the convenience to understand the mode of change of heat resistance with acclimation time, however, it is required to express the resistance of each acclimation group in terms of single index. For this reason, the sum of the survival percentages for 5 hours, i.e. the 5 -hour cumulative per cent survival, was calculated and used as index of heat resistance. In such a case as the present, the median or $50 \%$ survival time is usually adopted. But this value was found to show a much larger extent of experimental fluctuation than the cumulative value. So the writer preferred the latter index to the former. 

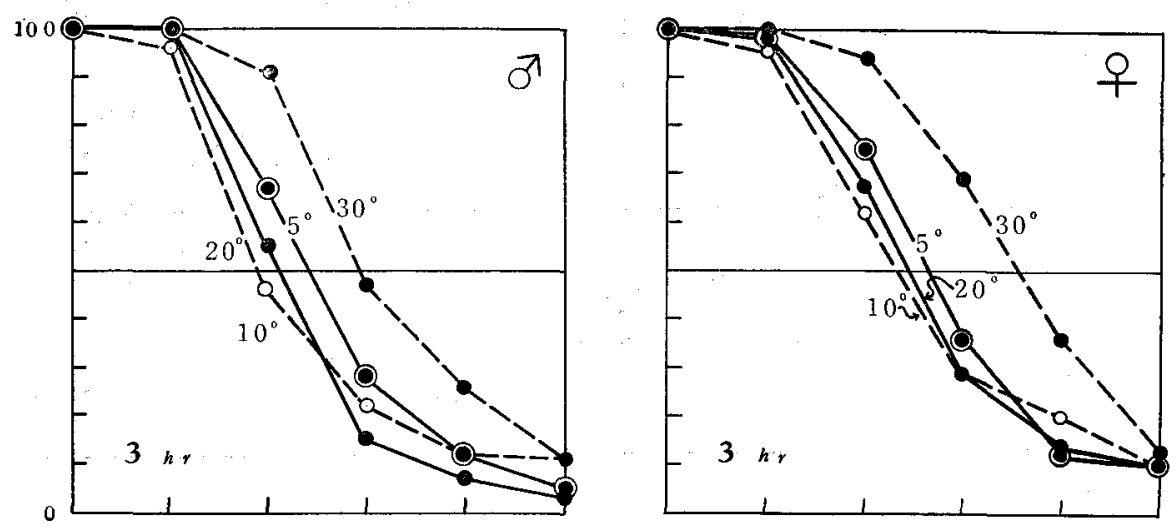

A
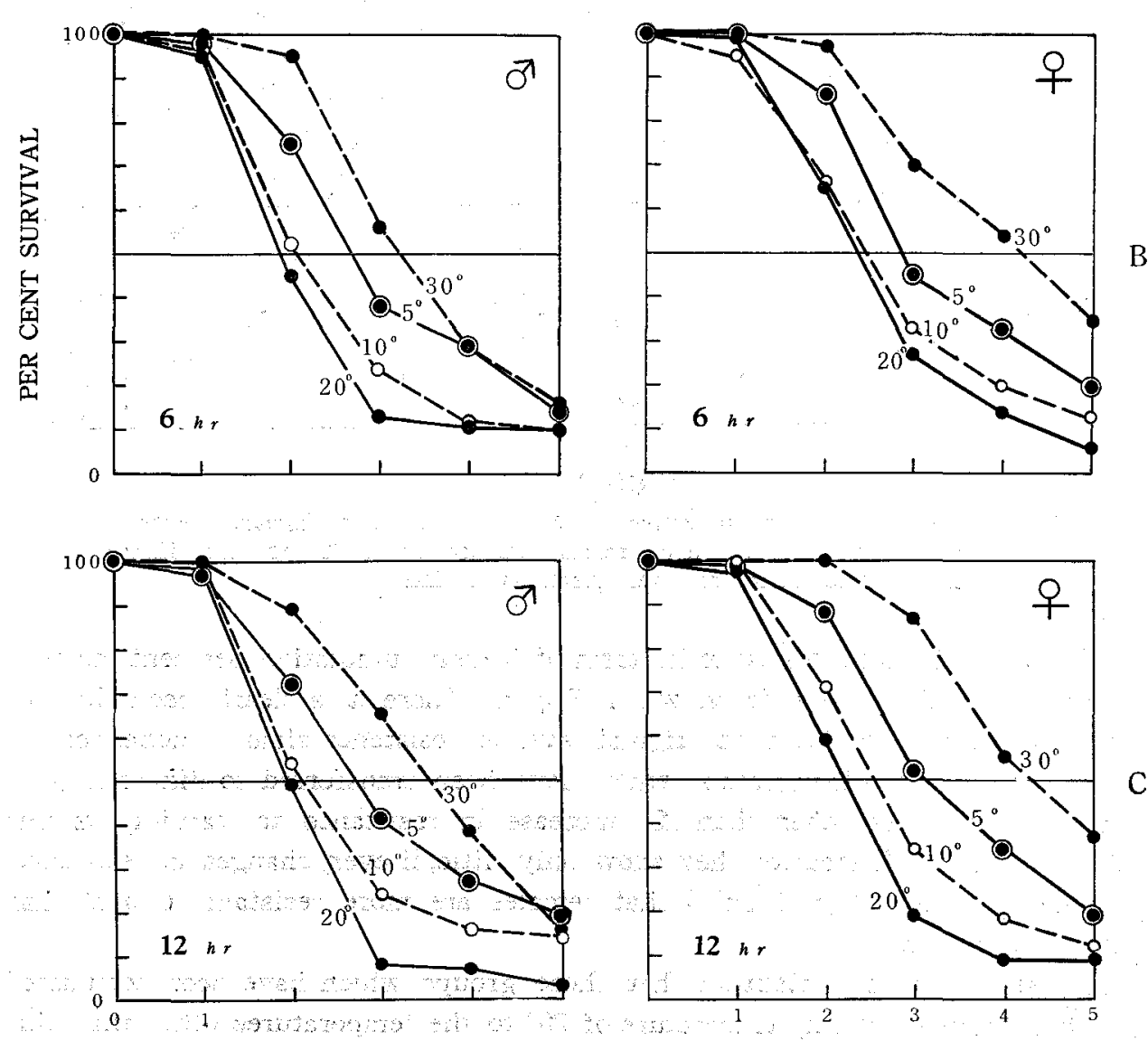

TIME IN HOURS 


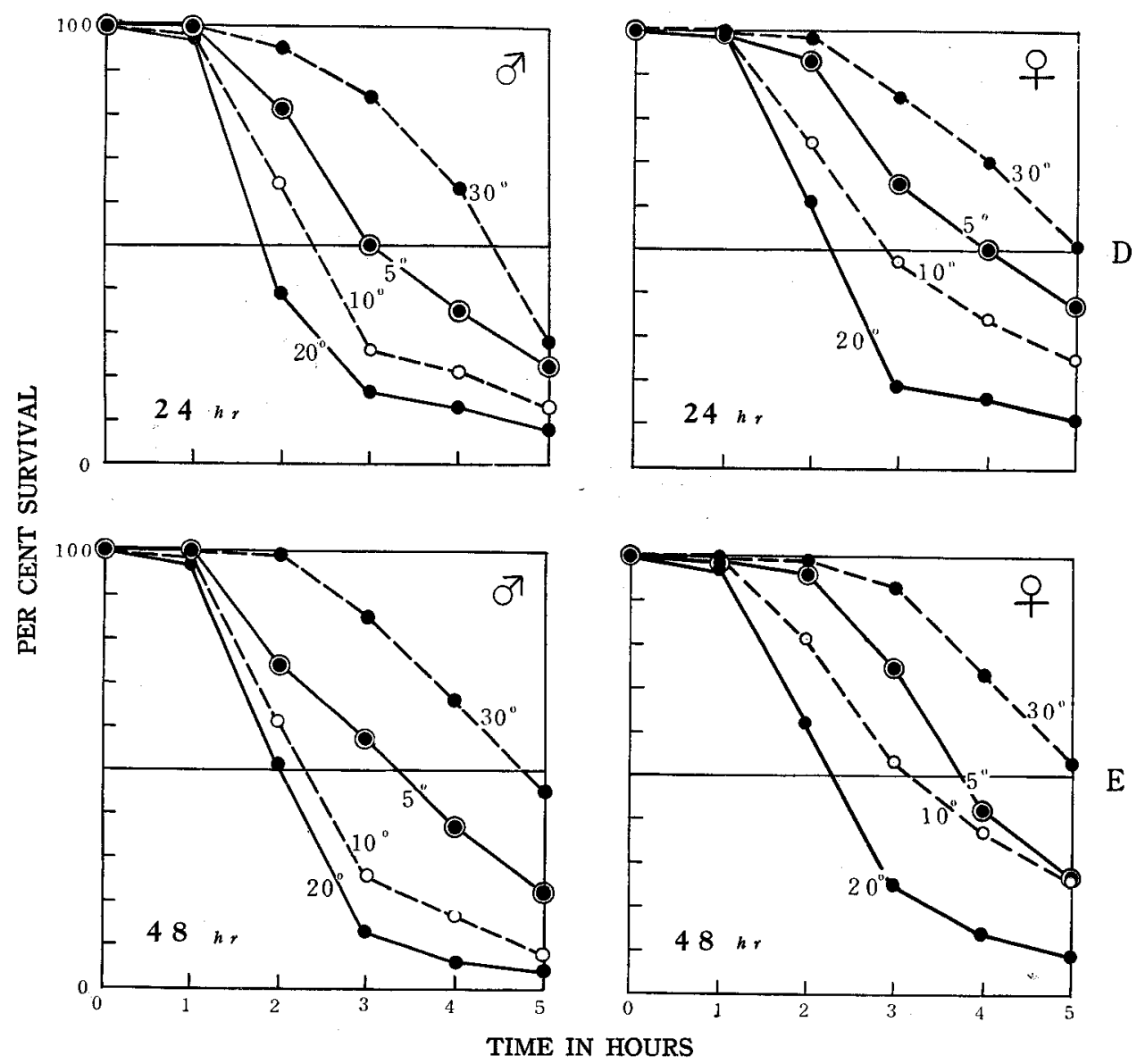

Fig. 2 (A-E). Time-survival curves at $38.6^{\circ} \mathrm{C}$ of adults of Tigriopus japonicus acclimated from the same rearing temperature of $20^{\circ}$ to four different temperatures stated for given durations of time.

Change of the heat resistance in terms of 5-hour cumulative per cent survival in each acclimation group is shown in Fig. 3. There it is clearly seen that the control $20^{\circ}$ group maintains its original level of resistance almost unchanged for 48 hours while the other groups which have been transferred to different acclimation temperatures other than $20^{\circ}$ increase in resistance to varying extents within 24 hours. Thereafter they show only little, if ever, changes in resistance. It is evident from Figs. 2 and 3 that females are more resistant to heat than males in every case.

It deserves special attention that those groups which have been acclimated from their original rearing temperature of $20^{\circ}$ to the temperatures other than this acquire heat resistance without exception, and that of the two groups acclimated to the lower temperatures the $5^{\circ}$-acclimated gains decidedly greater heat resistance 
than the $10^{\circ}$-acclimated does. This phenomenon is inconsistent with the general rule of temperature acclimatization acknowledged extensively among poikilotherms that a rise in acclimation temperature entails a gain in heat resistance and a loss in cold resistance while a fall in acclimation temperature results in the reverse

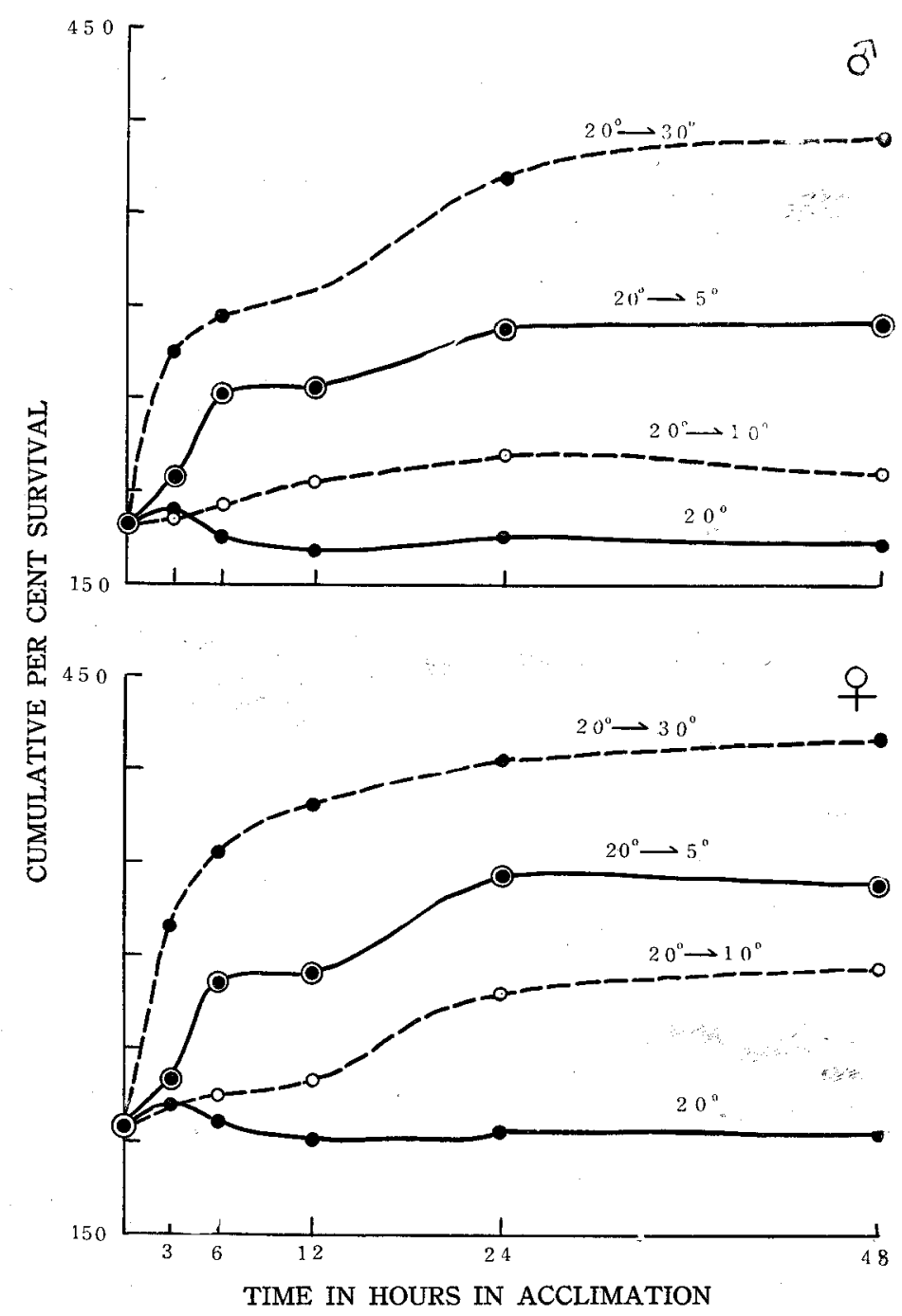

Fig. 3. Change of the heat resistance of adults of Tigriopus japonicus, as indicated by 5 -hour cumulative per cent survivals at $38.6^{\circ} \mathrm{C}$, with the duration of time after transfer from a rearing temperature of $20^{\circ} \mathrm{C}$ to four different acclimation temperatures.

(for crustaceans, SPOor 1955, Ranade 1957). This general rule is also found true in many cases of geographical and seasonal adaptation in heat resistance (for crustaceans, e.g. BOVJERG 1952, KROG 1954). 
In plants and poikilotherms other than crustaceans, however, there are a few examples of such a peculiar relation as has been shown in the present experiment (cf. Precht 1958). SAPper (1935) has observed that cold-acclimated plants have not only high cold resistance but also high heat resistance. Dehydration appears to be involved in this case as one of the important factors. Tsukuda and OHSAwA (1959) have shown in the fresh-water red snail, Physa sp., that the heart rate of animals acclimated to $20^{\circ}$ drops at higher temperatures than that of $25^{\circ}$-acclimated animals. HART (1952) has found in the fresh-water fish, Micropterus salmoides, that the northern race withstands higher temperatures better than the southern race. A similar phenomenon has been reported in the periwinkle, Nodilittorina granularis (OHSAwa and Tsukuda 1956).

The phenomenon that Tigriopus gains heat resistance when it is acclimated from $20^{\circ}$ to $30^{\circ}$ may have some underlying mechanism in common with the phenomenon of temperature acclimatization generally observed in poikilotherms. It is, however, impossible to apply the same principle to the acquirement of heat resistance by Tigriopus acclimated from $20^{\circ}$ to the lower temperatures. Here arise two important questions that have to be answered by further researches: Can a mere change in the environmental temperature, irrespective of its direction, induce an increase in heat resistance?; and, is the cause of the increased heat resistance the same in quality whether the environmental temperature is raised or lowered? The former appears improbable since, as has been reported (MATUTANI 1959), a respective higher level of resistance once acquired by Tigriopus that has been acclimated from $20^{\circ}$ to another temperature is maintained as such as long as 240 hours. If heat resistance were gained through a stimulus which is nothing but a fall in the environmental temperature, it would be lost within a much shorter duration of time. The latter question requires a physiological approach.

\section{Experiment 2.}

\section{Change of heat resistance according to acclimation temperature in animals reared at four different temperatures}

The foregoing experiment has revealed a peculiar phenomenon that Tigriopus reared at $20^{\circ}$ gains heat resistance when it is acclimated to $10^{\circ}$ and $5^{\circ}$ as well as when it is acclimated to $30^{\circ}$, giving a U-shaped acclimation temperature-heat resistance curve with a minimum resistance value at $20^{\circ}$. This phenomenon appeared to point to a possibility that the heat resistance of Tigriopus might increase, whether it was warmed or cooled, in function of, so to say, the absolute value of the difference between the rearing temperature and an acclimation temperature. To examine this possibility, animals reared at four different temperatures were acclimated respectively to four temperatures and the change of heat resistance was traced. 


\section{Materials and methods}

Tigriopus was reared at $5^{\circ}, 10^{\circ}$ and $20^{\circ}$ for 180 days and at $30^{\circ} \mathrm{C}$ for 30 days. It was found impossible to keep animals at $30^{\circ}$ for a longer period than 30 days without any significant effect of selection. From these cultures adult animals were transferred to four acclimation temperatures of $5^{\circ}, 10^{\circ}, 20^{\circ}$ and $30^{\circ} \mathrm{C}$, at which they were maintained for 24 and 48 hours before they were tested for their heat resistance (Fig. 4). The culture of animals and the heat resistance test were made in the same way as described above.

About 3200 individuals were used for a series of tests, which was repeated 11 times, and average values were calculated from the results.

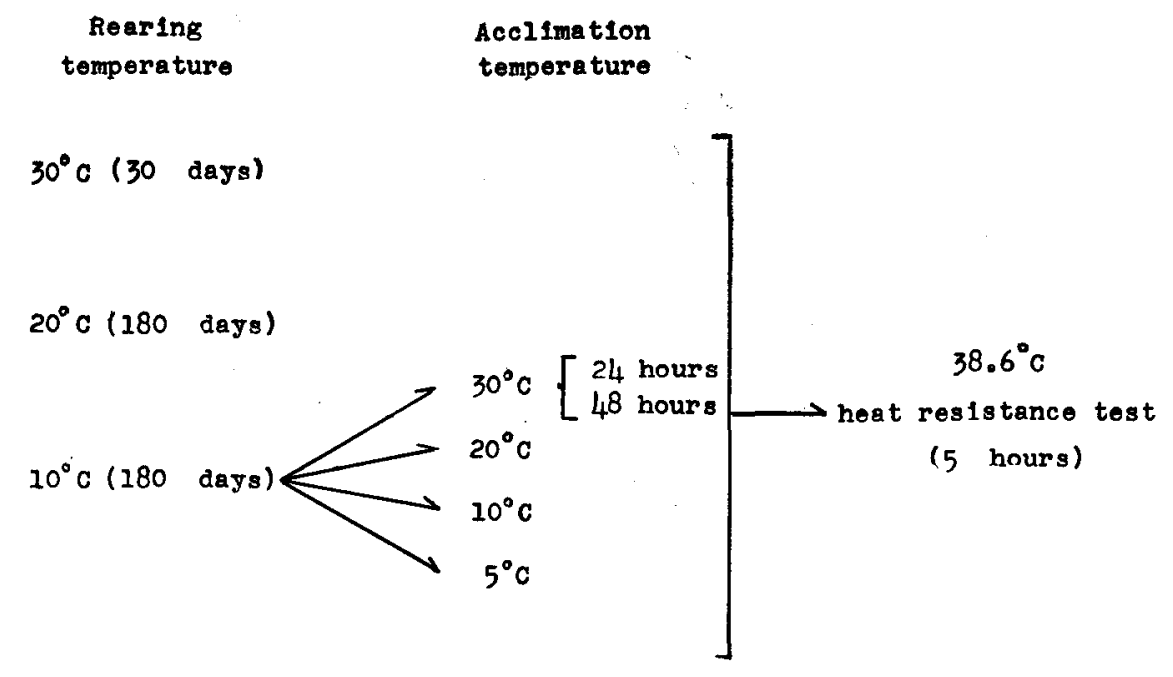

Fig. 4. Procedure of experiment 2 .

\section{Results and consideration}

The results of the heat resistance test at $38.6^{\circ} \mathrm{C}$ are shown in Figs. 5 and 6. These time-survival curves show complicated relationships between the rearing temperatures and the acclimation temperatures. In $30^{\circ}$-reared animals, the original high level of heat resistance is well preserved for 24 hours after transfer to the lower temperatures, but in 48 hours they show some variation due to the acclimation to the altered temperatures. In $20^{\circ}$-reared animals, on the contrary, the change of heat resistance is most pronounced, the resistance rising rapidly when animals are transferred to the lower temperatures as well as when they are acclimated to the higher temperatures. The increase in resistance is rapid in the order of $30^{\circ}, 5^{\circ}$ and $10^{\circ}$ acclimation. Among both $10^{\circ}$ - and $5^{\circ}$-reared animals, the 

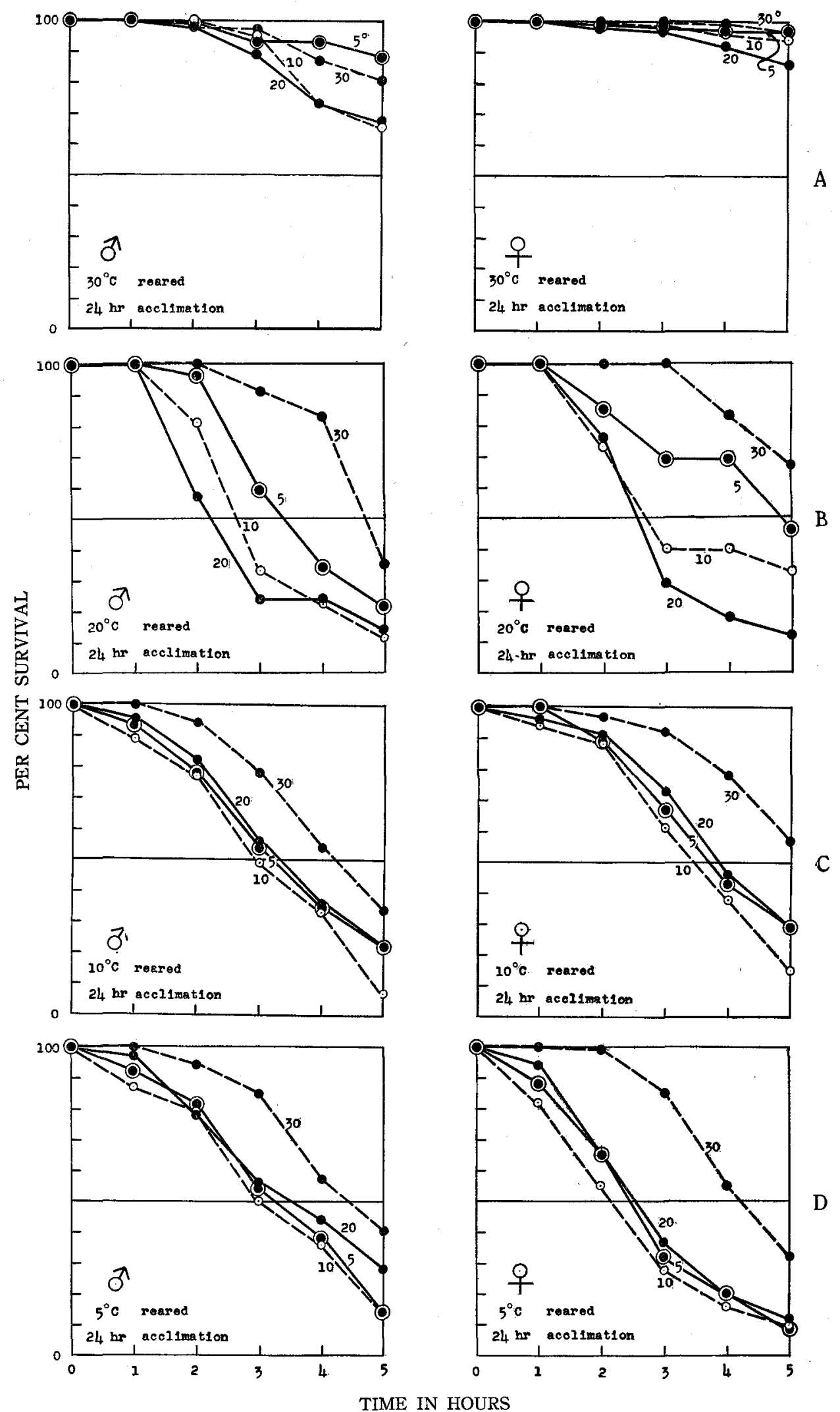

Fig. 5 (A-D). Time-survival curves at $38.6^{\circ} \mathrm{C}$ of adults of Tigriopus japonicus 24 hours after transfer from four different rearing temperatures to four different acclimation temperatures stated. 

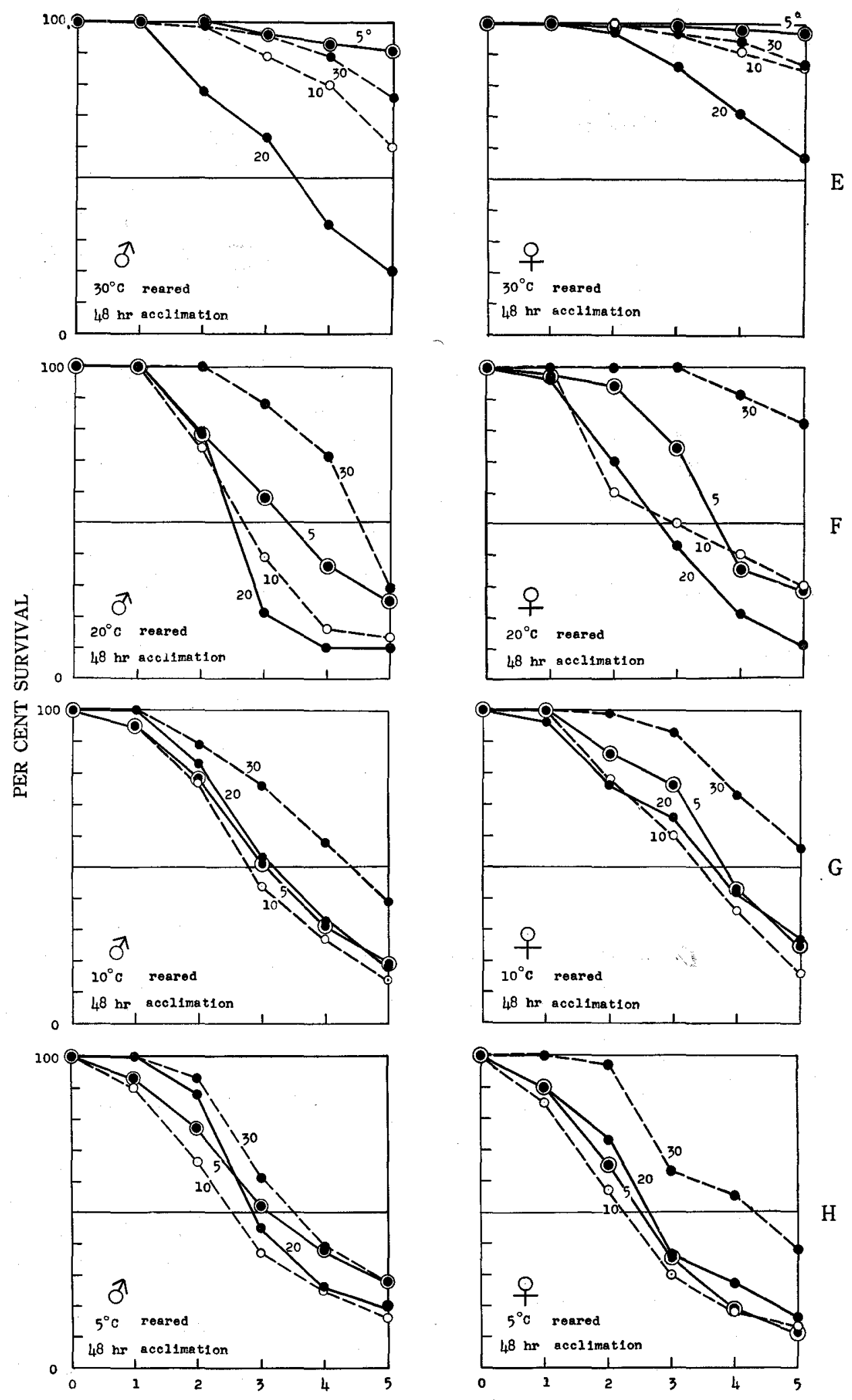

\section{TIME IN HOURS}

Fig. 6 (E-H). Time-survival curves at $38.6^{\circ} \mathrm{C}$ of adults of Tigriopus japonicus 48 hours after transfer from four different rearing temperatures to four different acclimation temperatures stated. 
change of heat resistance due to acclimation is little significant except in $30^{\circ}$ acclimation.

From each of these time-survival curves, the sum of per cent survivals for 5 hours, that is the 5 -hour cumulative per cent survival, was calculated as the index of heat resistance for the convenience of ready comparison of the mode of change of heat resistance among the acclimations. The result is shown in Fig. 7 , in which the indexes of resistance are plotted against acclimation temperatures.

These acclimation temperature-heat resistance curves are all characterized by the U-shape. In both $20^{\circ}$ - and $30^{\circ}$-reared animals, the lowest resistance is shown in $20^{\circ}$ acclimation. In $20^{\circ}$-reared animals, the highest resistance is attained by $30^{\circ}$ acclimation group in both sexes, while in $30^{\circ}$-reared animals the resistance of $5^{\circ}$ acclimation group appears somewhat higher than that of $30^{\circ}$ acclimation group. In $5^{\circ}-$ and $10^{\circ}$-reared animals, on the other hand, the highest resistance is shown in $30^{\circ}$ acclimation and the lowest resistance in $10^{\circ}$ acclimation. It is concluded, therefore, that $20^{\circ}$ - and $10^{\circ}$-reared animals gain heat resistance whether they are warmed or cooled, while heat resistance is reduced as a result of temperature change when $30^{\circ}$-reared animals are acclimated to $20^{\circ}$ and when $5^{\circ}$-reared animals are acclimated to $10^{\circ}$.

When Tigriopus is transferred from its rearing temperature to a different acclimation temperature, its heat resistance is considered to change gradually and to tend to a new stationary level which is proper to that acclimation temperature. On averages, the stationary level is higher in the order: $30^{\circ}>5^{\circ}>10^{\circ}>20^{\circ}$ of acclimation temperature in males; and $30^{\circ}>10^{\circ}>20^{\circ}>5^{\circ}$ in females.

The trend of heat resistance toward the stationary level in each case is illustrated in Fig. 8. Resistance increases rapidly in the animals warmed to $30^{\circ}$ from the lower temperatures and decreases also rapidly in the animals cooled from $30^{\circ}$ to $20^{\circ}$. The mode of change of resistance is, however, by no means simple. In some cases, a phenomenon of overshooting is acknowledged (Fig. $8 \mathrm{~B}$, $5^{\circ}$ acclimation; $\mathrm{D}, 10^{\circ}$ acclimation), and in some cases resistance appears to be in a fairly stable state before it reaches the stationary level (Fig. $8 \mathrm{C}, 20^{\circ}$ and $30^{\circ}$ acclimation; $\mathrm{G}, 30^{\circ}$ acclimation). In other cases, resistance initially changes in the opposite direction to the stationary level (Fig. $8 \mathrm{~A}, 5^{\circ}$ acclimation) and then returns back to the level (Fig. $8 \mathrm{D}, 20^{\circ}$ acclimation; F, $5^{\circ}$ acclimation; $\mathrm{G}$, $20^{\circ}$ acclimation; $\mathrm{H}, 10^{\circ}$ acclimation).

Heat resistance which, in most cases, is still changing 48 hours after transfer is supposed to reach eventually the corresponding stationary level when temperature acclimatization is completed. The time required for complete acclimatization will depend on the temperature of acclimation on the one hand and on the difference between the rearing and the acclimation temperature on the other. If, however, there has taken place some genetic variation associated with heat 


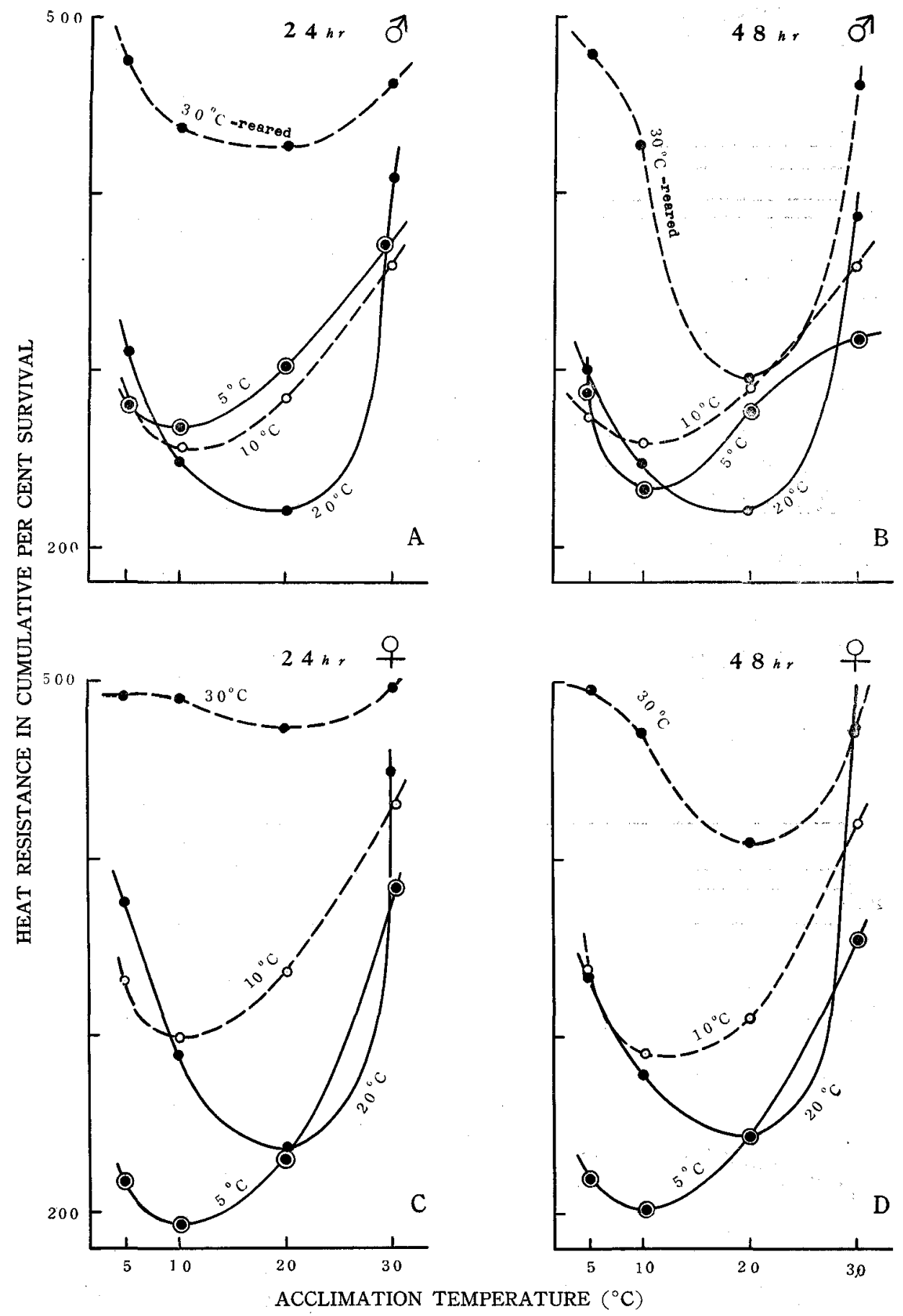

Fig. 7. Heat resistance of adults of Tigriopus japonicus, as indicated by 5-hour cumulative per cent survivals at $38.6^{\circ} \mathrm{C}, 24$ and 48 hours after transfer from four different rearing temperatures stated to four different acclimation temperatures. 

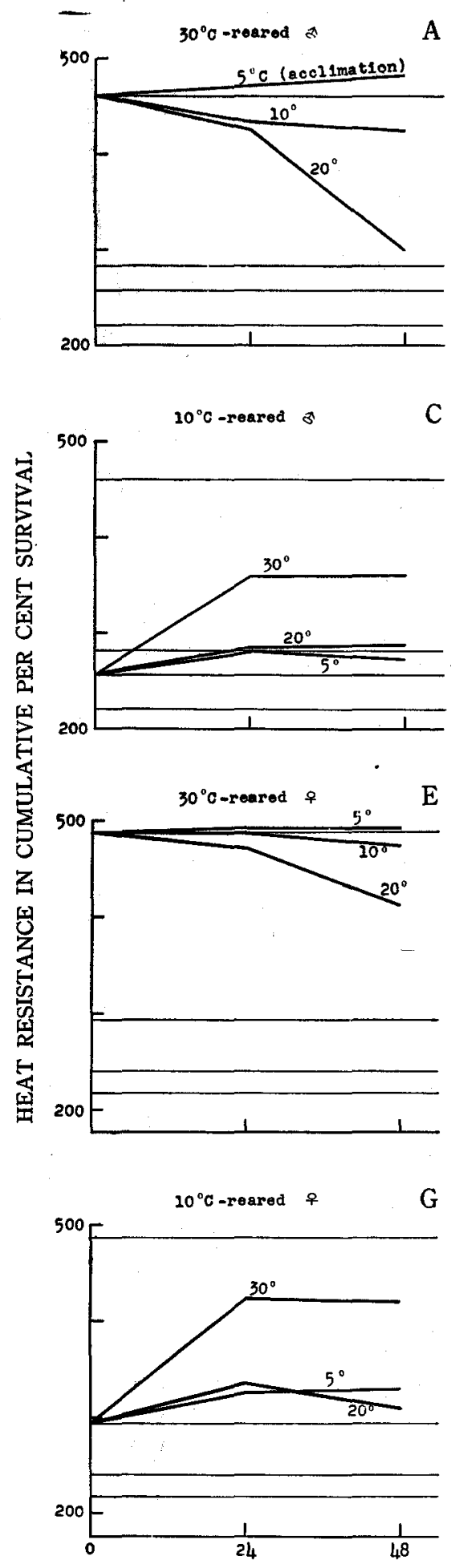

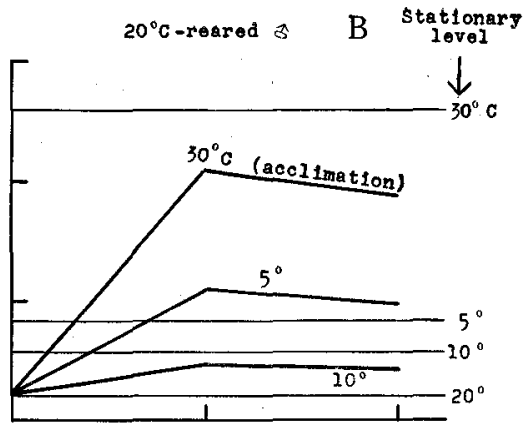

$5^{\circ}$-reared o D
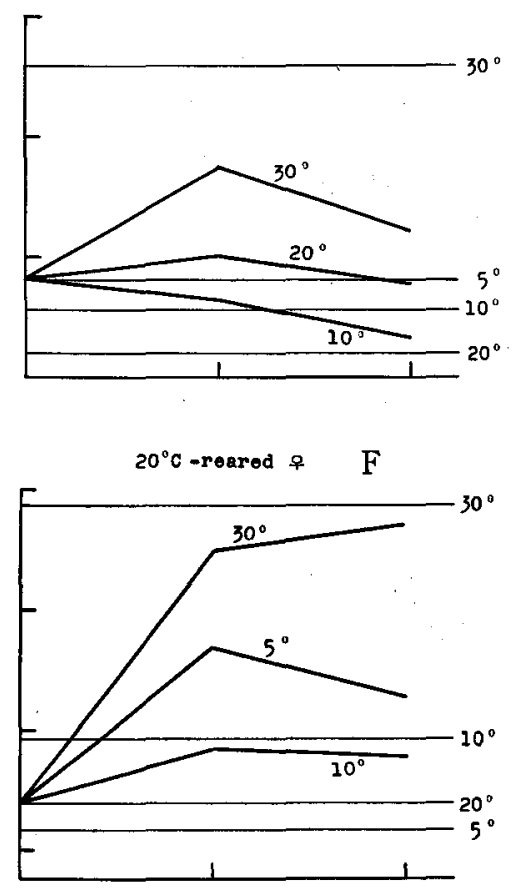

5"C -reared 우 $\mathrm{H}$

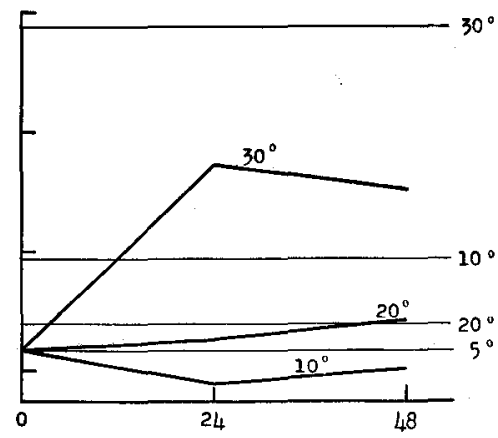

ACCLIMATION

Fig. 8. Change of heat resistance of adults of Tigriopus japonicus as indicated by 5-hour cumulative per cent survivals at $38.6^{\circ} \mathrm{C}, 24$ and 48 hours after transfer from the rearing temperatures, $5^{\circ}, 10^{\circ}, 20^{\circ}$ and $30^{\circ} \mathrm{C}$ to four different acclimation temperatures stated. Fine horizontal lines indicate stationary levels of heat resistance to be reached when acclimatization is completed at the acclimation temperatures. 
resistance in a temperature group of animals during the culture extending over several months, the stationary level may be different from that which is estimated.

Fig. 8 shows the absolute rate of change of heat resistance. Since the acclimation temperature-heat resistance curves are not linear and the stationary levels are not equally spaced, it may be necessary to take into consideration the relative

Table 1. Change of heat resistance of adults of Tigriopus japonicus, reared at four different temperatures, 24 and 48 hours after transfer to four acclimation temperatures, in percentages of the change from the original stationary level of heat resistance for a rearing temperature to the level for an acclimation temperature, and direction of change (arrows) to reach the latter level, negative signs showing changes reverse in direction to those indicated by arrows.

\begin{tabular}{|c|c|c|c|c|c|c|c|c|c|}
\hline & \multirow{3}{*}{ अ } & \multicolumn{8}{|c|}{ Acclimation temperature $\left({ }^{\circ} \mathrm{C}\right)$} \\
\hline 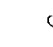 & & \multicolumn{2}{|c|}{$5^{\circ}$} & \multicolumn{2}{|c|}{$10^{\circ}$} & \multicolumn{2}{|c|}{$20^{\circ}$} & \multicolumn{2}{|c|}{$30^{\circ}$} \\
\hline & & after $24 \mathrm{hr}$ & $\mathrm{r}$ after $48 \mathrm{hr}$ & after $24 \mathrm{hr}$ & after $48 \mathrm{hr}$ & after $24 \mathrm{hr}$ & after $48 \mathrm{hr}$ & after $24 \mathrm{hr}$ & after $48 \mathrm{hr}$ \\
\hline \multirow{4}{*}{ 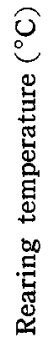 } & $5^{\circ}$ & & & $\begin{array}{c}\downarrow \\
63\end{array}$ & $\begin{array}{c}\downarrow \\
174\end{array}$ & $\begin{array}{c}\downarrow \\
-33\end{array}$ & $\downarrow$ & $\begin{array}{c}\uparrow \\
52\end{array}$ & $\begin{array}{c}\uparrow \\
22\end{array}$ \\
\hline & $10^{\circ}$ & $\stackrel{\uparrow}{100}$ & $i_{74}$ & & & $\begin{array}{c}\downarrow \\
-86\end{array}$ & $\begin{array}{c}\downarrow \\
-86\end{array}$ & $\begin{array}{c}\uparrow \\
51\end{array}$ & $\begin{array}{c}\uparrow \\
51\end{array}$ \\
\hline & $20^{\circ}$ & $\begin{array}{c}\uparrow \\
138\end{array}$ & $\stackrel{\uparrow}{120}$ & $\begin{array}{c}\uparrow \\
72\end{array}$ & $\underset{66}{\uparrow}$ & & & $\stackrel{\uparrow}{79}$ & $\underset{71}{\uparrow}$ \\
\hline & $30^{\circ}$ & $\stackrel{\downarrow}{-6}$ & $\begin{array}{c}\downarrow \\
-11\end{array}$ & $\begin{array}{c}\downarrow \\
15\end{array}$ & $\begin{array}{c}\downarrow \\
19\end{array}$ & $\begin{array}{l}\downarrow \\
14\end{array}$ & $\begin{array}{c}\downarrow \\
66\end{array}$ & & \\
\hline
\end{tabular}

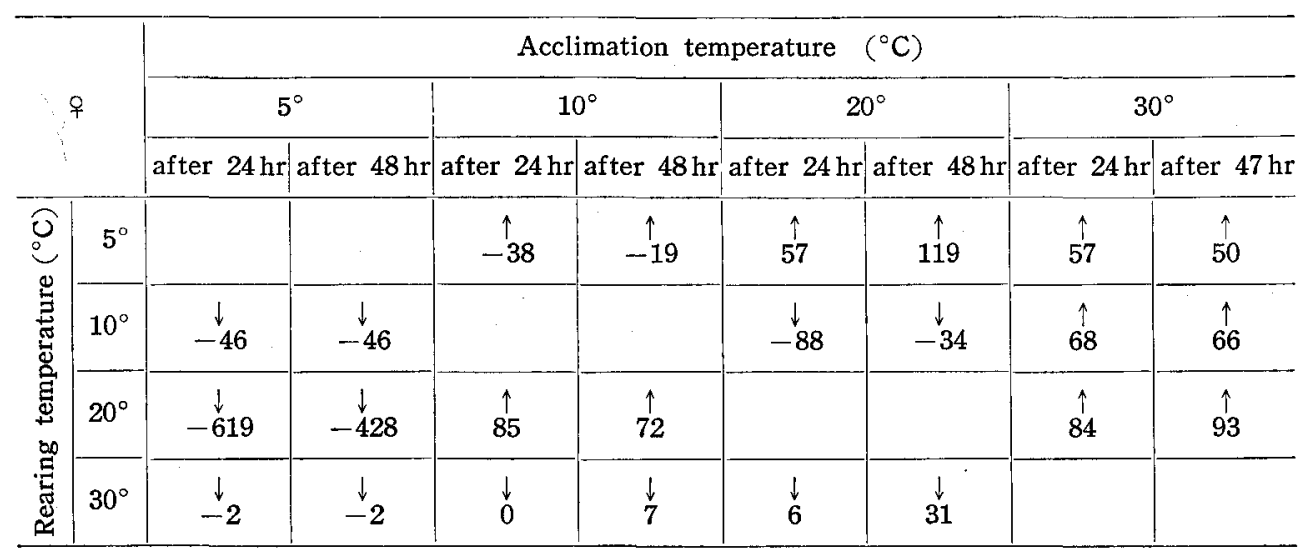

rate besides the absolute rate of change of heat resistance. In this connection, Table 1 was made up in which the relative rate of change is given in percentages of the whole change from an original stationary level to a new stationary level to be reached when acclimatization is completed.

Fig. 8 and Table 1 show that the initial direction and the rate of change 
vary significantly according not only to acclimation temperature but also to rearing temperature. It was stated by a number of investigators (LOEB and WASTENEYS 1912, Doudoroff 1942, BRETT 1944, 1946) and is generally accepted that gain of heat resistance of poikilotherms in acclimation to higher temperatures is much more rapid than loss in acclimation to lower temperatures. The present data have many respects which contradict with this statement as the data obtained by TsukUda (1960) with the guppy, Lebistes reticulatus, have. The rule certainly holds good between $20^{\circ}$ and $30^{\circ}$ but does not over the whole range of temperature from $5^{\circ}$ to $30^{\circ}$, which is conceivably due to the complicated relationship between acclimation temperatures and heat resistance such as represented by the U-shaped curves.

In the greenfish, Girella nigricans, DOUDOROFF (1942) observed an initial rise before gradual decline of heat resistance in fish acclimated from $26^{\circ}$ to $14^{\circ}$. Spoor (1955) also noticed a similar phenomenon in the crayfish, Orconectes rusticus, transferred from $22^{\circ}-26^{\circ}$ to $4^{\circ}$. Such initial rises are acknowledged in the present data, not only in acclimation to lower temperatures (Fig. $8 \mathrm{~A}$ and E, $5^{\circ}$ acclimation; $\mathrm{F}, 5^{\circ}$ acclimation; $\mathrm{G}, 5^{\circ}$ acclimation) but also in the case of loss of heat resistance in acclimation to higher temperatures (Fig. $8 \mathrm{C}, \mathrm{D}$ and G, $20^{\circ}$ acclimation).

\section{Experiment 3 .}

\section{Cyanide resistance of Tigriopus japonicus in relation to acclimation temperature}

The resistance to cyanide of Tigriopus acclimated to different temperatures was tested to see whether there are or there are not physiological differences other than that in heat resistance between the individuals which have gained heat resistance through acclimation to a high temperature of $30^{\circ}$ and those which have become resistant to heat through acclimation to low temperatures of $10^{\circ}$ and $5^{\circ}$.

\section{Materials and methods}

Tigriopus was kept in a mass at $19^{\circ} \mathrm{C}$ for 30 days. From this culture adult animals were transferred to four different acclimation temperatures of $2^{\circ}, 9^{\circ}, 9^{\circ}$ and $28^{\circ} \mathrm{C}$, at which they were maintained for 4,20 and 46 hours, in the same way as described above, before they were tested for their resistance to cyanide. The test was made by keeping them by 100 individuals in a hemispherical glass bowl, $55 \mathrm{~mm}$ in diameter, containing $22 \mathrm{ml}$ of $\mathrm{M} / 20 \mathrm{NaCN}$ sea water at $19^{\circ} \mathrm{C}$, for 2 hours during which mortalities were recorded every 15 minutes (Fig. 9). 
Results and consideration

From each time-per cent survival curve obtained, the 2-hour cumulative per cent survival, i.e., the sum of survival percentages observed every 15 minutes for 2 hours, was computed as in the case of the heat resistance test described in the foregoing chapters. Using this value as the index of cyanide resistance, the acclimation temperature-cyanide resistance curves were drawn (Fig. 10).

These curves indicate that there are pronounced differences in cyanide resistance among the four temperature acclimation groups, which vary significantly with time. After 4 hours in acclimation, the lower the acclimation temperature, the greater is cyanide resistance. Then cyanide resistance increases relatively rapidly with time in $28^{\circ}$-acclimated animals, while it decreases appreciably in $9^{\circ}$-acclimated males and $2^{\circ}$-acclimated females. In $20^{\circ}$-acclimated males and $9^{\circ}$-acclimated females, however, the decreasing change of cyanide resistance is little significant.

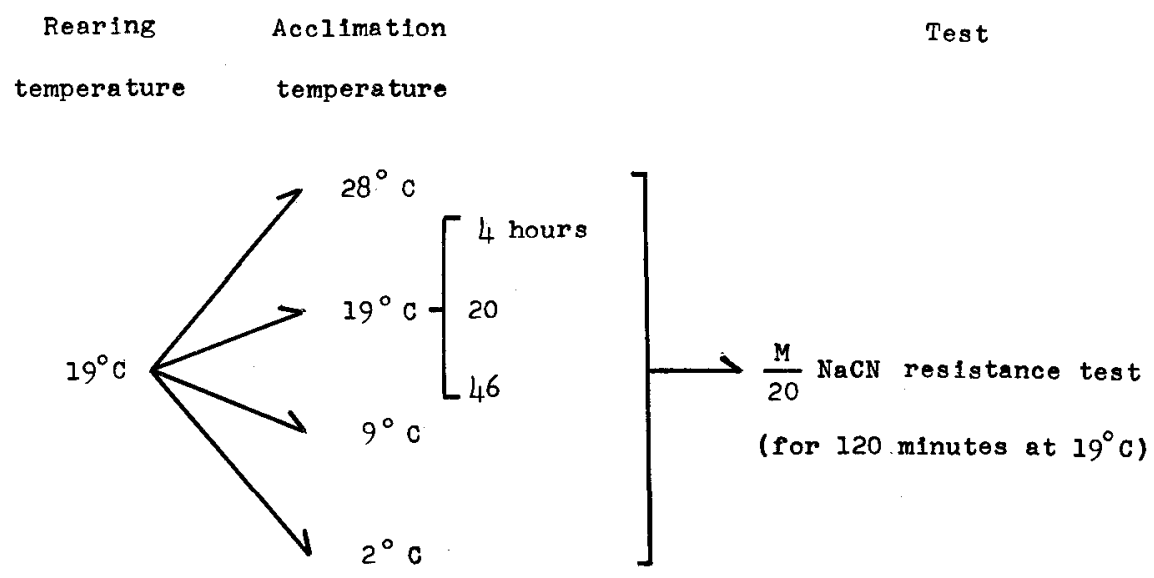

Fig. 9. Procedure of experiment 3.

Since cyanide inhibits oxidative processes, a high level of cyanide resistance is considered as indicating primarily a depressed activity of aerobic metabolism, which in turn is perhaps associated with a reduced rate of oxygen consumption. It is a well established fact that the rate of oxygen consumption of poikilotherms decreases with falling temperature within the normal range of temperature (for crustaceans, c.f. MARshall and OrR 1955; also see Bullock 1955, Fry 1957, PRECHT 1958), and it has also been demonstrated by many investigators (Sayle 1928, Kirberger 1953, Blazka 1955, Kanungo and Prosser 1959) that temperature acclimation has usually a compensatory effect on the rate of oxygen consumption.

When animals acclimatized completely to $19^{\circ}$ are transferred from this rearing temperature to $2^{\circ}$, they become considerably inactive, remaining almost immobile 
at the bottom of vessel, probably, in a state of chill coma. In this state, their metabolism is supposed to be extremely depressed. Those individuals which have fallen into such a state do not restore readily their activity after they are returned back to $19^{\circ}$. If, however, they are kept longer at $19^{\circ}$, their activity recovers to some extent owing to 'capacity adaptation or acclimatization' (PRECHT 1958). In fact, some of $2^{\circ}$-acclimated animals were observed to swim slowly $2-3$ days after transfer. The gradual decrease of cyanide resistance in $2^{\circ}$-acclimated females (Fig. 10) certainly indicates the effect of capacity acclimatization in aerobic metabolism. In males, the effect is far less explicit in $2^{\circ}$ acclimation than in $9^{\circ}$ acclimation.

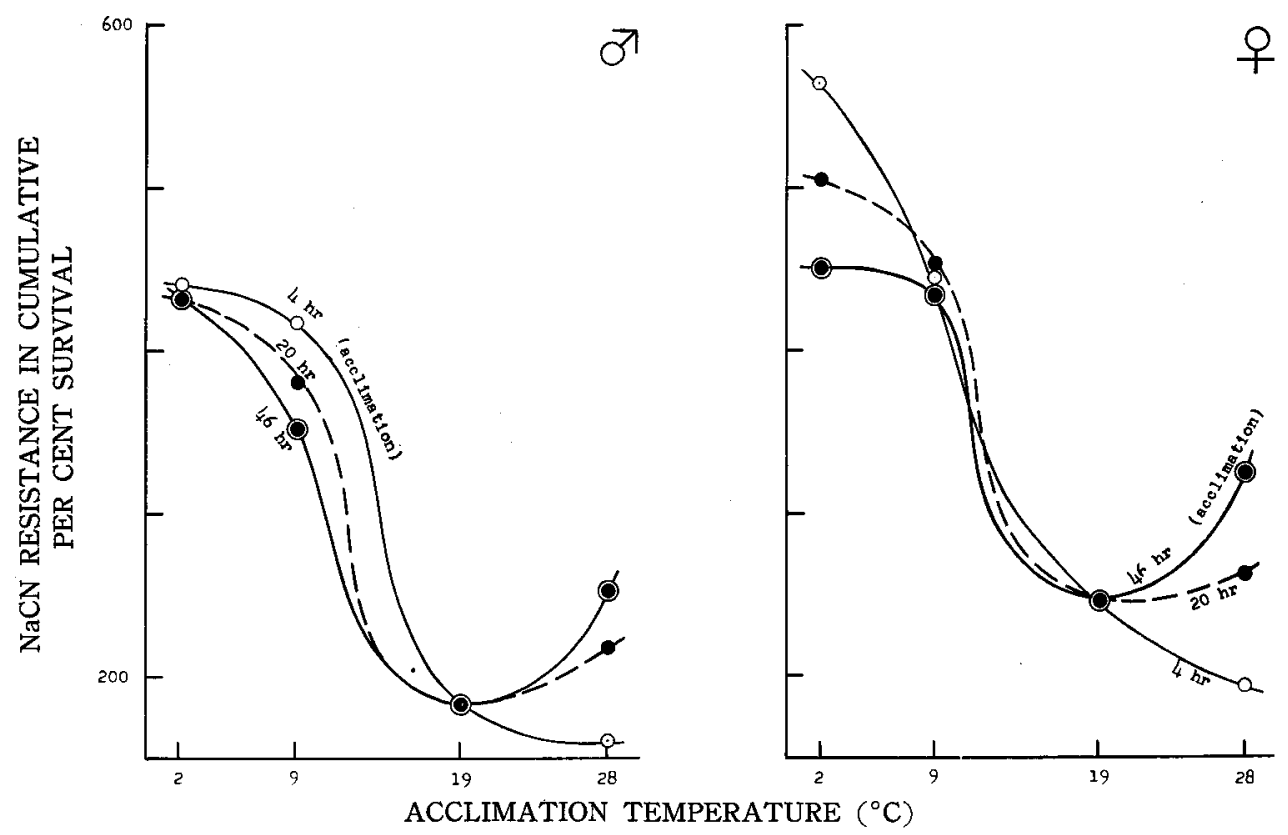

Fig. 10. Cyanide resistance of adults of Tigriopus japonicus, 4 (empty circles), 20 (solid circles) and 46 (double solid circles) hours after transfer from a rearing temperature of $19^{\circ} \mathrm{C}$ to four different acclimation temperatures. Cyanide resistance is indicated by 2 -hour cumulative per cent survivals in $\mathrm{M} / 20 \mathrm{NaCN}$ sea water at $19^{\circ} \mathrm{C}$, observed at intervals of 15 minutes.

When, on the other hand, $19^{\circ}$-reared animals are transferred to $28^{\circ}$, their activity increases. Very low values of cyanide resistance for individuals acclimated to $28^{\circ}$ for 4 hours reflect the activated state of aerobic metabolism. Here also capacity acclimatization is evidently acknowledged in individuals acclimated to $28^{\circ}$ for prolonged periods. The appreciable gains in cyanide resistance in $28^{\circ}$ acclimation indicate such a compensatory effect.

Comparing the result obtained by this experiment with those obtained by

$$
-150-
$$


the foregoing, some parallelism is perceived between cyanide resistance and heat resistance over the range of acclimation temperature from $2^{\circ}$ to $19^{\circ}$. But the relation cannot be applied to $28^{\circ}$ acclimation in which cyanide resistance is still far lower than that in $9^{\circ}$ acclimation even after 48 hours while the heat resistance of $30^{\circ}$-acclimated animals exceeds that of $5^{\circ}$-acclimated animals within 24 hours of acclimation (Figs. 7 and 10). Sumner and Doudoroff (1938) have shown that fish acclimated to $30^{\circ}$ are more resistant to cyanide, urethane and oxygen lack than those acclimated to $10^{\circ}$ when compared at $20^{\circ}$. This relationship suggesting a reduced oxygen requirement as a result of acclimation to the high temperature agrees with that observed between $19^{\circ}$ and $28^{\circ}$ but does not with that observable among the temperatures lower than $19^{\circ}$ in the present data.

The results obtained show that there are more or less distinct differences in aerobic metabolism between animals acclimated to $2^{\circ}$ and $9^{\circ}$ and those acclimated to $28^{\circ}$, and suggest that the acquirement of heat resistance at the low acclimation temperatures is different in mechanism from that at the high acclimation temperatures.

\section{Experiment 4.}

\section{Temperature acclimatization in the heat resistance of Tigriopus japonicus in relation to environmental oxygen concentration}

The preceding experiment has indicated a high degree of probability that the acquirement of heat resistance at the low acclimation temperatures is caused by the inactivation of aerobic metabolism due to cooling. This suggests a possibility that if the metabolic activity of animals is depressed by some agent other than coldness, they will also gain heat resistance. To examine this possibility, Tigriopus was acclimated to $20^{\circ}$ and $30^{\circ}$ in high and low concentrations of oxygen.

\section{Materials and methods}

Adult animals of Tigriopus sampled at random from the $20^{\circ}$ culture were put by 100 individuals into a test tube, $30 \mathrm{~mm}$ in diameter by $195 \mathrm{~mm}$ long, containing $85 \mathrm{ml}$ of sea water of a given oxygen saturation at an acclimation temperature of $20^{\circ}$ or $30^{\circ}$. The test tube thus prepared was immediately closed with a rubber stopper and kept at that acclimation temperature for 35 or 59 hours before the animals were tested for their heat resistance in the same way as was described previously. The apparatus used for controlling the oxygen concentration in acclimation sea water is schematically illustrated in Fig. 11. To decrease the concentration of oxygen in sea water nitrogen gas flowed through the tubing $L$ was bubbled into sea water in the equilibration $\operatorname{tank} B$ which was 
immerged into a water bath $A$ controlled thermostatically at a given temperature. The flux of nitrogen gas was measured by a graduated cylinder $F$ and was controlled by cocks. Sea water was sampled at times from the tank $B$ through the tubing $C$ and the oxygen concentration was examined by the Winkler method. When the latter was decreased to a required level, sea water was introduced into the test tube for acclimation $K$ which had been filled with nitrogen gas at the

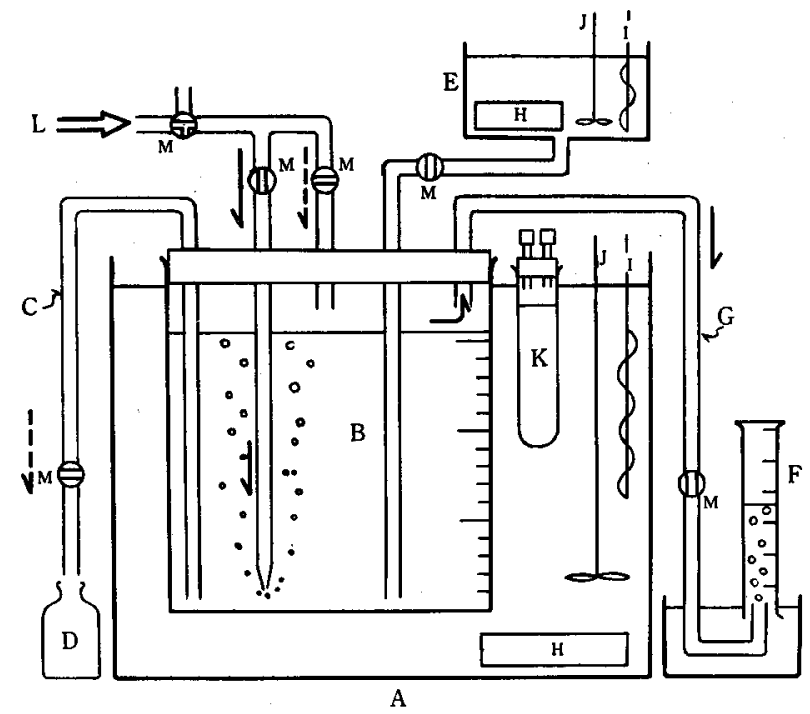

Fig. 11. Schematic diagram of the apparatus to obtain sea water of a given level of oxygen concentration.

A : thermostatic water bath.

$B$ : sea water tank for equilibration. of temperature and of nitrogen gas.

C : glass tubing for drawing out sea water from the tank.

D : Winkler flask.

$\mathrm{E}$ : reservoir for supplying sea water.

F : graduated cylinder for measuring the flux of nitrogen gas.

G : glass tubing for gas exhaust.

$\mathrm{H}$ : heater.

I : regulator.

J : stirrer.

$\mathrm{K}:$ test tube for acclimation.

$\mathrm{L}$ : inlet for nitrogen gas.

$\mathrm{M}$ : cocks.

acclimation temperature. To obtain sea water of high oxygen saturations, aerated sea water piped from the reservoir $E$ was kept in the tank $B$ for about 24 hours without bubbling in thermal equilibrium with the water bath $A$. Thus, high and low levels of oxygen concentration were prepared for either acclimation temperature (Fig. 12). 


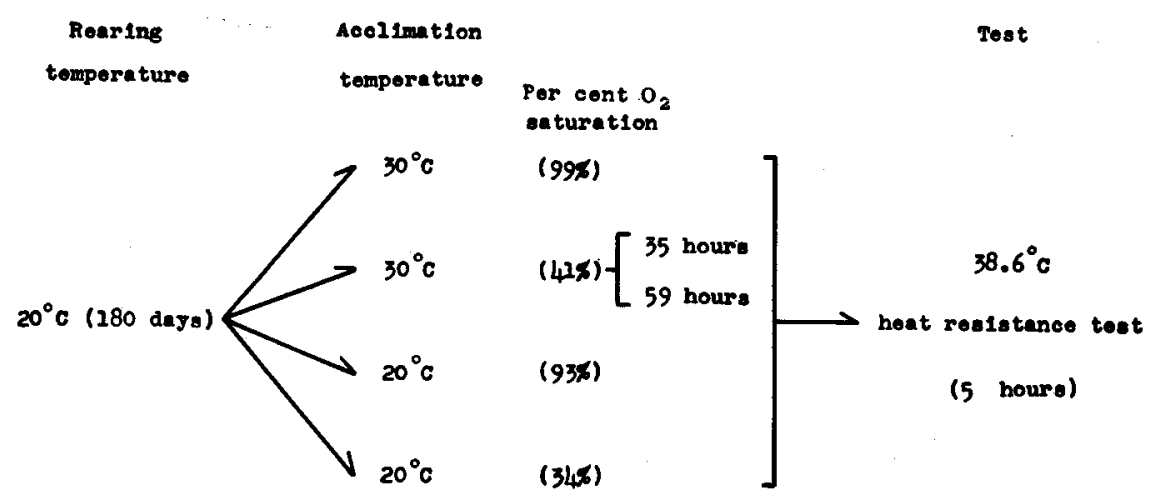

Fig. 12. Procedure of experiment 4.

\section{Results and consideration}

The results obtained are shown in Fig. $13 \mathrm{~A}$ and $\mathrm{B}$ in the time-survival relations, from which it is obvious that $30^{\circ}$-acclimated animals are by far more resistant to heat than $20^{\circ}$-acclimated ones and that animals acclimated at low levels of oxygen saturation are always significantly more heat resistant than those acclimated at high levels.

BRETT (1944, 1946) found in the bullhead, Ameiurus nebulosus, that a continuous low oxygen saturation of the water in the acclimation tank inhibited acclimatization to heat up to 23 hours. Namely, fish acclimated from $20^{\circ}$ to $28^{\circ}$ in adequate oxygen saturation which ranged from 64 to $74 \%$ appeared to have completed virtually temperature acclimatization within 23 hours, while those acclimated from $17^{\circ}$ to $27^{\circ}$ in very low oxygen saturation which ranged from 2 to $26 \%$ showed a distinct lack of acclimatization. He considered that oxygen played some positive role in the mechanism of heat acclimatization. His findings apparently conflict with the present results. It must be noticed, however, that the level of insufficient oxygen adopted by Brett is extremely low in comparison with that used in the present experiment and that the level of sufficient oxygen adopted by him is also markedly low. Exact comparison is, therefore, impossible between the two data. In Tigriopus, the acclimation in $10.7 \% \mathrm{O}_{2}$ saturation was found impracticable causing 22 to $35 \%$ mortalities, though the acclimation in $34 \%$ or $41 \% \mathrm{O}_{2}$ brought about no ill effect. Superposing the present data on the Brett's, it would be suggested that there might be an optimal $\mathrm{O}_{2}$ concentration for temperature acclimatization to take place. But, this conception should be evaluated by a further investigation.

At all events, Tigriopus appears to be relatively sensitive to oxygen deficiency, and its aerobic metabolism is supposed to be suppressed not a little in such low levels of oxygen as $34 \%$ and $41 \%$. This inactivated state must have some 


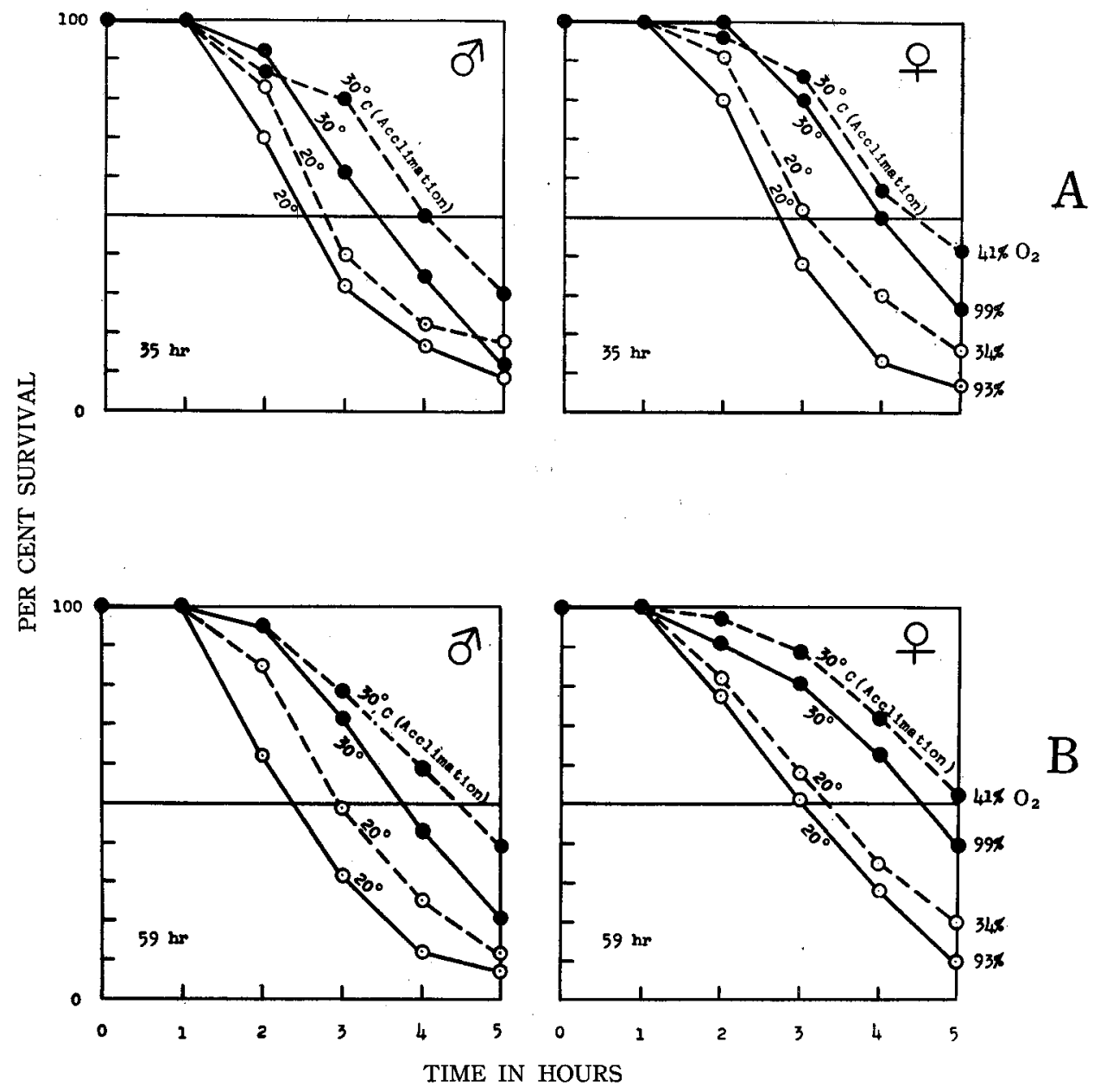

Fig. 13 (A-B). Time-survival curves at $38.6^{\circ} \mathrm{C}$ of adults of Tigriopus japonicus acclimated to $20^{\circ}$ (empty circles) and $30^{\circ} \mathrm{C}$ (solid circles) for 35 and 59 hours at high (solid lines) and low (broken lines) levels of $\mathrm{O}_{2}$ saturation.

favorable effect on the heat resistance of animals in the subsequent exposure to a high temperature.

\section{Experiment 5.}

\section{Heat resistance in relation to salinity, of Tigriopus japonicus acclimated to dilute and concentrated sea waters}

The foregoing series of experiments has been focused on the mechanism through which Tigriopus gains heat resistance when it is warmed or cooled 
from its optimal temperature. Viewed from such a standpoint, the present experiment is rather secondary in nature. As already mentioned, salinity is without doubt an environmental factor for Tigriopus no less important than temperature. It is expected that the former is closely associated with the latter in their effects on the physiology of Tigriopus as it is in their fluctuations in the natural environment of this species. So it is highly interesting not only from the physiological viewpoint but also from the ecological viewpoint to see how the heat resistance of this species is related with ambient salinity.

\section{Materials and methods}

Adults of Tigriopus japonicus from the culture in $100 \%$ sea water $(18.46 \%$ Cl) at $20^{\circ} \mathrm{C}$ were acclimated to $25 \%$ and $150 \%$ of sea water for definite periods

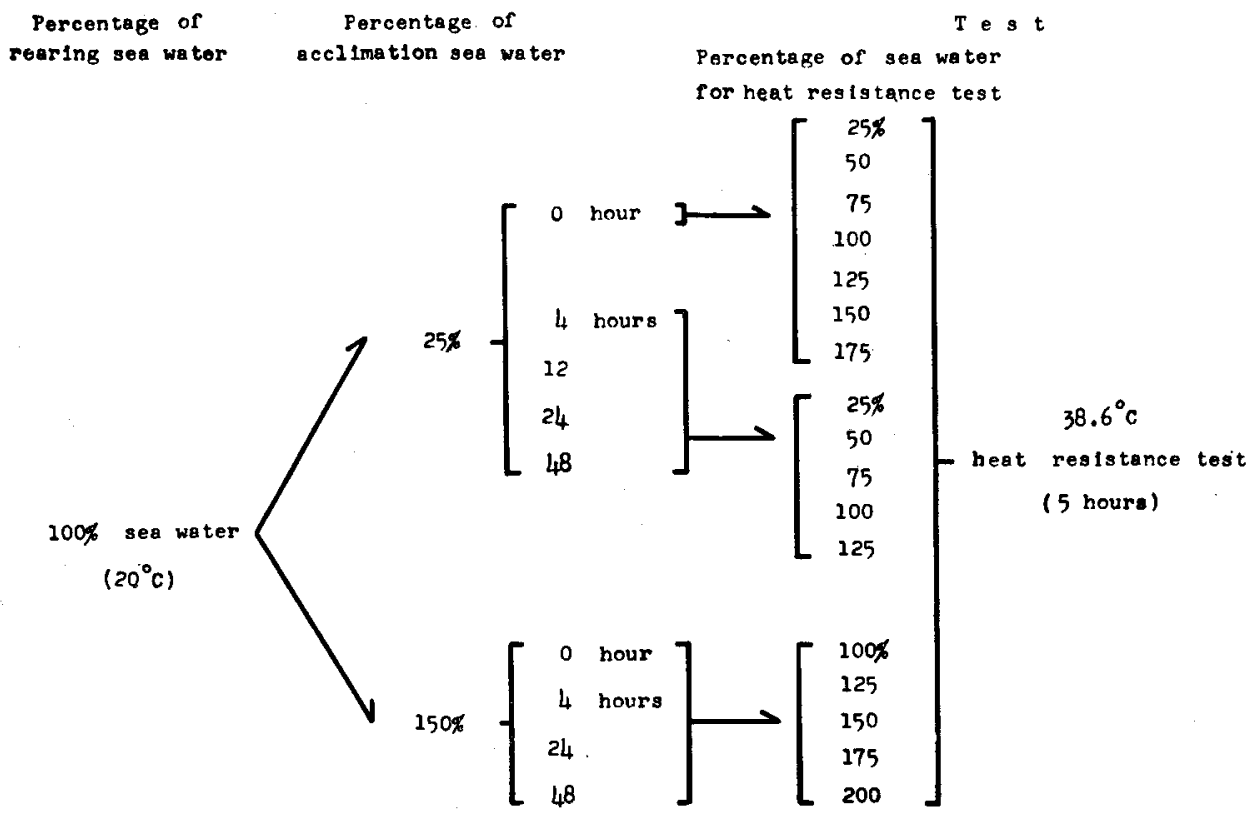

Fig. 14. Procedure of experiment 5 .

of time as shown in Fig. 14. Then they were tested for their heat resistance, as described above, in various per cent concentrations of sea water (Fig. 14). The concentrations used for either salinity acclimation group were within the range of concentration to which Tigriopus could be transferred without deleterious effects at $20^{\circ} \mathrm{C}$ (MAtUtani, unpublished data).

Various concentrations of sea water were obtained by diluting $200 \%$ sea water, which was prepared by evaporation' at a temperature below $40^{\circ} \mathrm{C}$, with fresh water purified by ion exchange. 


\section{Results and consideration}

For the convenience of comparison, the values of heat resistance, expressed in 5-hour cumulative per cent survivals, are plotted against the per cent concentration of test sea water in Figs. 15 and 16.

The 0 hour curves i.e. curves for the control $100 \%$-acclimated animals have their apexes at $150 \%$ without exception and are almost symmetric in shape falling down gradually on either side of this concentration. When animals are acclimated to $25 \%$ sea water, their heat resistance markedly decreases on the whole with the duration of acclimation time and at the same time the concentration in which they show the highest resistance to heat becomes lower (Fig. 15). After 48 hours of acclimation, the maximum resistance is given at $50 \%$ in males and at $75 \%$ in females. In 150\%-acclimated animals, on the other hand, heat resistance increases pronouncedly within 24 hours of acclimation and then it decreases to some extent (Fig. 16). After 4 hours, the increase in resistance is much larger on the higher concentration side of $150 \%$ than on the lower side. After 24 hours, curves become much flattened, especially in females, and the concentration in which resistance is highest is found shifted to $175 \%$ from 150\%. After 48 hours, however, resistance falls appreciably on the higher side in males and on both lower and higher sides in females, though it is well preserved in $150 \%$ in both sexes.

There are not a few cases reported with various animal forms and with different levels of organization in which heat resistance is higher in hypertonic media than in isotonic or hypotonic media. This is the case, for example, with the frog muscle (Vernon 1899), Paramecium (Hutchinson 1913, 1915) and the periwinkle, Nodilittorina granularis (OHSAwA and Tsunuda 1956). There is however an optimum salinity, for $100 \%$ sea water-acclimated animals to withstand heat, at about $150 \%$ sea water, above which resistance decreases. Tok1okA and Suzuki (1939) reported the similar tendency.

The phenomenon that the heat resistance of marine invertebrates increases with the salinity to which they are acclimated has also been observed by some authors. Thus, KINNE (1958) has shown that the heat resistance of the polychaete, Nereis diversicolor, the amphipod, Gammarus duebeni, and the isopod, Sphaeroma hookeri, is lowered in low salinity-adapted animals and raised in high salinity-adapted animals. According to his view, one cause for the shift of heat resistance is obviously the alteration of water and ionic balance in animals under stress. It is likely that dehydration is involved in this phenomenon, which can increase general protoplasmic resistance to extreme temperatures (PRECHT 1958).

There is at present no information available on the osmotic relation of Tigriopus to its medium, though there are detailed studies on the osmotic regulation of Gammarus (BeAde and CRAGG 1940) and Artemia (Croghan 1958 a, b). 


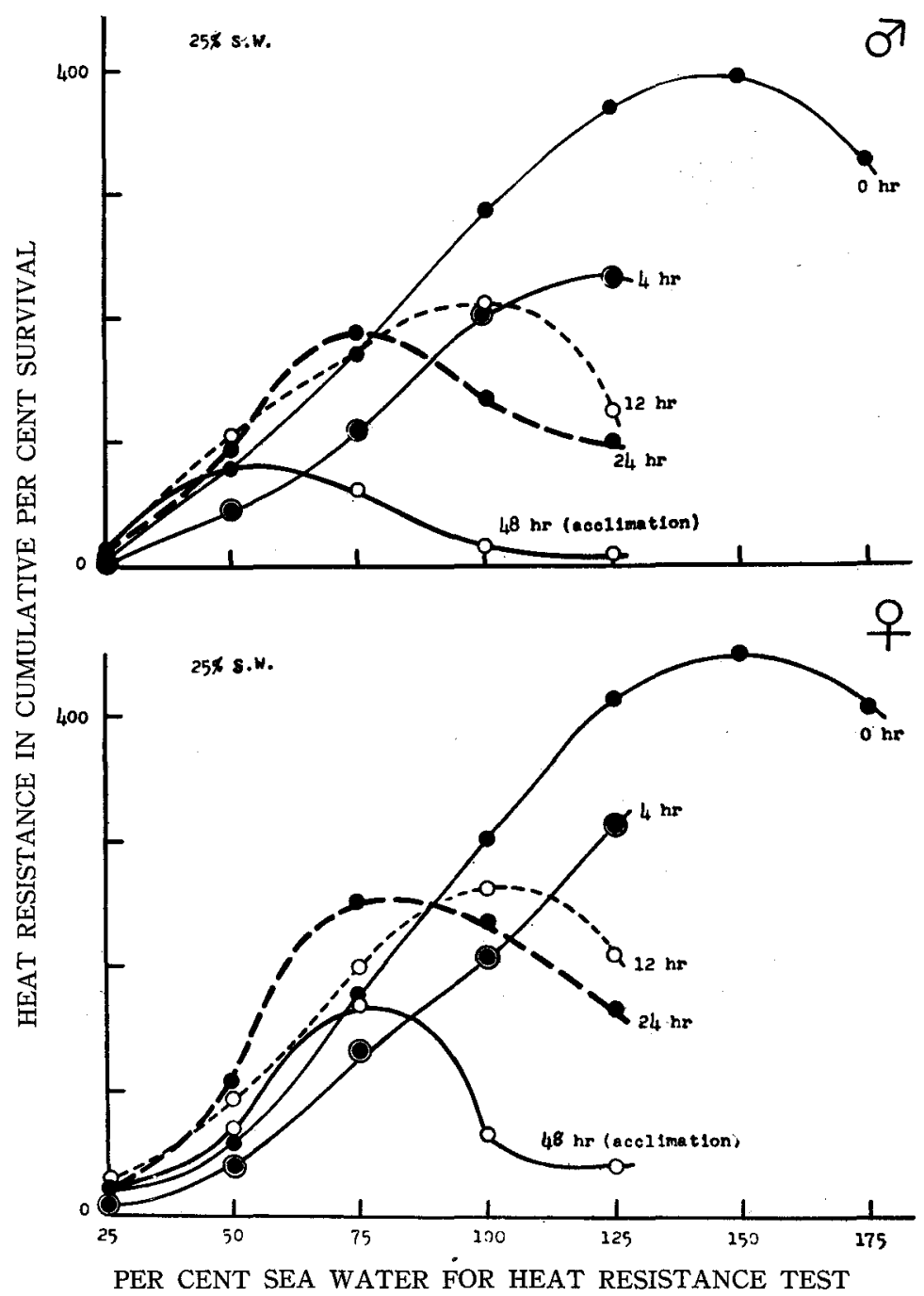

Fig. 15. Heat resistance in various per cent concentrations of sea water of adults of Tigriopus japonicus acclimated from a rearing concentration of $100 \%$ to $25 \%$ sea water at $20^{\circ} \mathrm{C}$ for definite lengths of time from 4 to 48 hours. Heat resistance is indicated in 5 -hour cumulative per cent survivals at $38.6^{\circ} \mathrm{C}$. 


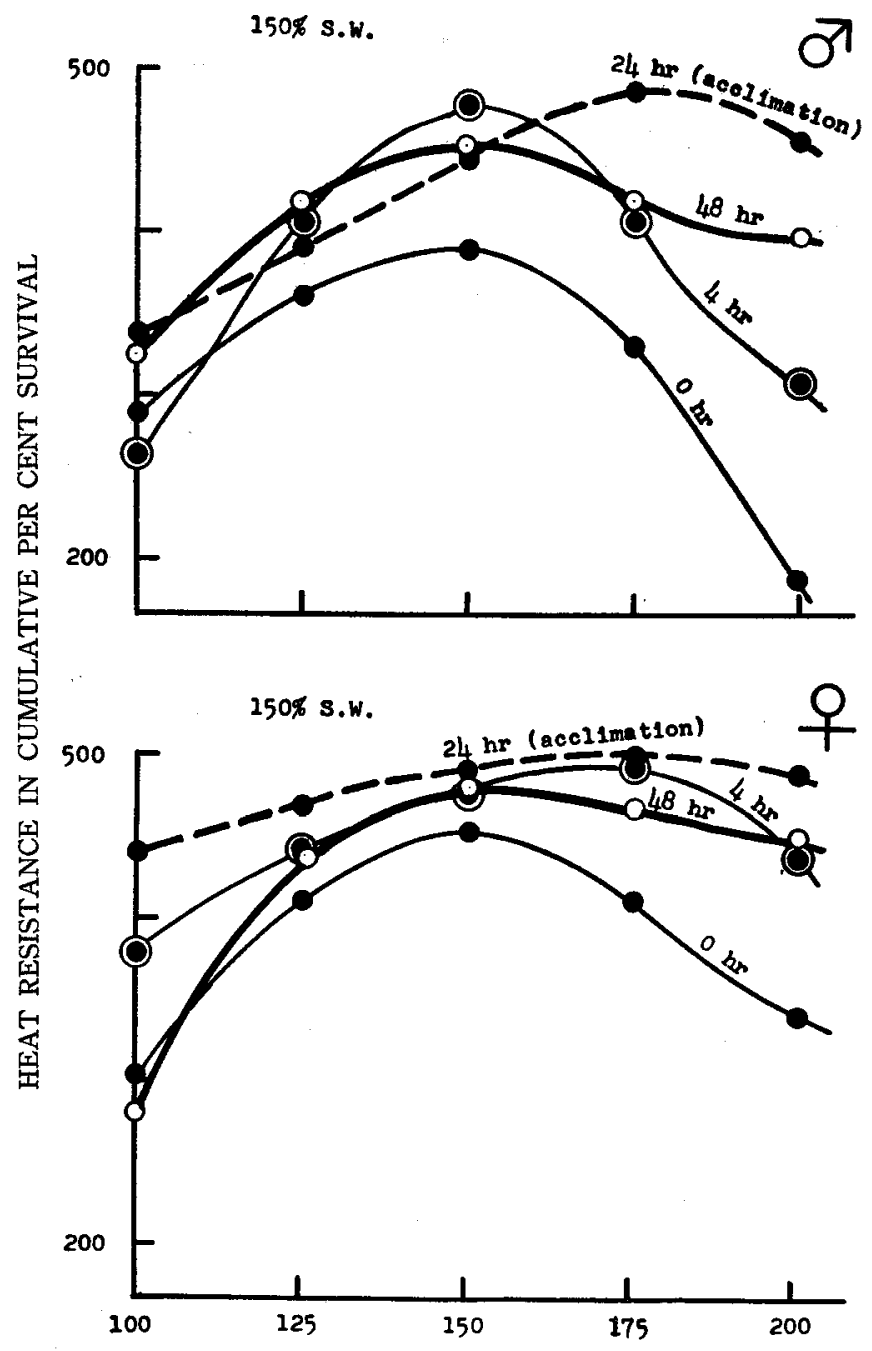

PER CENT SEA WATER FOR HEAT RESISTANCE TEST

Fig. 16. Heat resistance in various per cent concentrations of sea water of adults of Tigriopus japonicus acclimated from a rearing concentration of $100 \%$ to $150 \%$ sea water at $20^{\circ} \mathrm{C}$ for definite lengths of time from 4 to 48 hours. Heat resistance is indicated in 5 -hour cumulative per cent survivals at $38.6^{\circ} \mathrm{C}$. 
The relatively rapid decrease of the optimum salinity for heat resistance in $25 \%$ sea water-acclimated animals and the little increase of the optimum salinity in $150 \%$ sea water-acclimated animals appear to indicate that the ability of osmotic regulation of this species is comparatively low in the hypotonic medium and high in the hypertonic medium. But there is no reason to regard the shift of the optimum salinity as reflecting the osmotic property of animals. It is, nevertheless, indubitable that Tigriopus is euryhaline, a fact which suggests a high degree of probability that it possesses a somewhat evolved osmoregulatory function in comparison with its pelagic relatives. At any rate, the explanation of the phenomena observed must wait for further experiments.

Apart from the consideration on the underlying physiological processes, the relations obtained by the present experiment are very suggestive from the ecological point of view. Tide pools inhabited by Tigriopus are situated well above the high tide mark and rarely overflowed by waves unless the sea is

raging. Sea water in such tide pools are readily concentrated by evaporation or diluted with rain water. Ordinarily, an extreme elevation of water temperature under the direct sun in summer months is accompanied with accerelated concentration by evaporation. The increase of heat resistance in a hypertonic medium is certainly advantageous for the life of Tigriopus. On the other hand, a rapid elevation of water temperature after a heavy rain, if it occurs, will constitute a crisis.

\section{Discussion}

The present study was undertaken for the purpose of elucidating the process of temperature acclimatization in the heat resistance of the eurythermal copepod Tigriopus japonicus. Exp. 1 revealed an unexpected phenomenon that heat resistance was gained not only by animals acclimated from $20^{\circ}$, to $30^{\circ}$ but also by those acclimated from $20^{\circ}$ to lower temperatures. This finding has orientated the subsequent study in the direction of investigating the mechanism of acquisition of heat resistance in low temperature acclimation in comparison with that in high temperature acclimation.

The possibility that a change in the ambient temperature, whether upward or downward, might alone induce an increase in heat resistance has been denied by Exp. 2, which showed that heat resistance was markedly reduced in many cases, when the ambient temperature was changed, e.g., from $30^{\circ}$ to $20^{\circ}$ and from $5^{\circ}$ to $10^{\circ}$.

Then it has remained as the most important problem whether the mechanism underlying the acquisition of heat resistance in low temperatures is or is not the same in nature with that in high temperatures. Animals acclimated to $5^{\circ}$ or $10^{\circ}$ appear to be so different in their general physiological conditions from those 
acclimated to $30^{\circ}$ that it is quite unlikely that the mechanisms should be the same. The former are in a state like chill coma for some time after transfer, while the latter show much increased activity. Phenomenally it can be said that inactivation at low temperatures and activation at high temperatures bring about the same result which is the gain of heat resistance. Those relations seem to diminish very much the probability that heat resistance is gained through the same process in low temperature-acclimated animals and in high temperatureacclimated animals.

The working hypothesis preferred is that the acquisition of heat resistance at low temperatures is effected secondarily by the inactivation of general metabolism of animals and is accordingly altogether different in mechanism from that at high temperatures which is temperature acclimatization in the strict sense of the term. Temperature acclimatization in this sense is observable in many poikilotherms and may involves some fundamental alterations in their physiological properties. On the other hand, it is a problem difficult to interprete how the inactivation of metabolism causes the gain of heat resistance. A solution of the problem has perhaps to be pursued in the mechanism of heat death.

Concerning the mechanism of heat death, there are a few theories, none of which is decisive. The mechanisms may be different with different high temperatures at which resistance is tested and with different conditions of the resistance test. An important theory is that death at high temperatures is asphyxial (cf. FISHER 1958). Since the test temperature of $38.6^{\circ} \mathrm{C}$ is relatively low for a high lethal temperature, it seems more probable that on transfer to this temperature the metabolic rate of Tigriopus is elevated immediately up to the limit beyond which oxygen deficiency in tissues has a fatal effect than that the thermal alteration of body substances takes place in tissues. If the heat death of Tigriopus is asphyxial in the present case, the heat susceptibility of animals is directly related to their oxygen requirement at the test high temperature.

According to the experience of the writer, the optimum temperature for Tigriopus is $20^{\circ}$ or thereabout. Hence animals acclimated to $20^{\circ}$ are considered to have their physiological activities in most harmonized and efficient conditions. If such animals are put at the test temperature, their metabolic rate is accerelated extremely till at last heat death occurs. In animals acclimated to $30^{\circ}$ the metabolic activity becomes decreased through temperature acclimatization and, when exposed to the test temperature, it does not rise so high as in $20^{\circ}$-acclimated animals. This contributes to heat resistance. On the other hand, when animals are acclimated to low temperatures such as $5^{\circ}$ and $10^{\circ}$, their metabolic activity becomes considerably suppressed, and, on transfer to the test temperature, metabolic rate is elevated far less readily in them than in $20^{\circ}$-acclimated animals. This results in an increased level of heat resistance.

Thus, it is inferred that so far as the range of temperature is concerned 
within which the acclimation experiments have been carried out, the higher the acclimation temperature, the greater is the effect of temperature acclimatization and the smaller is the effect of metabolic inactivation. Both effects would result jointly in the U-shaped acclimation temperature-heat resistance curves.

This theory finds strong support in the results obtained by Exp. 3 and also in the results by Exp. 4. The increased cyanide resistance in animals transferred to $20^{\circ}$ from the lower acclimation temperatures at the early period of acclimation indicates the inactivated state of aerobic metabolism in these animals, and the decreased cyanide resistance in animals transferred from the higher temperature the activated aerobic metabolism in them. Temperature acclimatization presents itself as an effect to reduce the differences in cyanide resistance.

In this case, however, cyanide-insensitive metabolism cannot be neglected. There is evidence suggesting the alteration of metabolic pattern as a result of acclimatization to temperature (EKBERG 1958) as in the case of acclimatization to oxygen (Prosser et al. 1957). After EkBERG, cold-acclimated goldfish depend relatively more on an active cyanide-sensitive path and warm-acclimated ones on an iodoacetate-sensitive path. There is, however, no information available at present on the cyanide-insensitive metabolism of Tigriopus. The problem is open for further study. The acquirement of heat resistance by animals acclimated to low oxygen can also be interpreted as resulting from the inactivation of aerobic metabolism under the condition of oxygen deficiency.

A dualistic conception about the mechanism of acquirement of heat resistance in Tigriopus has been concluded from the results of the present series of experiments. It is not clear whether this conception is restricted to Tigriopus or applicable to other poikilotherms. There is a possibility that such phenomena as have been observed in Tigriopus may be found in other forms if acclimation experiments are performed over relatively wide ranges of temperature, since, in Tigriopus, only simple relations showing the ordinary effect of temperature acclimatization would have been obtained if acclimation had been confined within a narrow range of temperature, say, from $20^{\circ}$ to $30^{\circ}$.

\section{Summary}

Change of heat resistance was investigated in relation to the environmental temperature and salinity with the euryplastic microcopepod, Tigriopus japonicus, which inhabits tide pools situated well above the high tide mark. Heat resistance was tested by exposing animals to $38.6^{\circ} \mathrm{C}$ for 5 hours and determining the mortality every hour in definite lengths of time after acclimation to various conditions.

1. When animals from $20^{\circ}$-reared culture were acclimated to four different temperatures of $5^{\circ}, 10^{\circ}, 20^{\circ}$ and $30^{\circ} \mathrm{C}$, the highest heat resistance is shown by $30^{\circ}$-acclimated individuals and the lowest resistance by $20^{\circ}$-acclimated ones, those 
acclimated to $5^{\circ}$ being next to the former in resistance. Thus $\mathrm{U}$-shaped acclimation temperature-heat resistance curves result in either sex over the range from $5^{\circ}$ to $30^{\circ} \mathrm{C}$.

2. When animals which have been reared at four temperatures of $5^{\circ}, 10^{\circ}$, $20^{\circ}$ and $30^{\circ}$ are respectively transferred to the four acclimation temperatures, also U-shaped acclimation curves are obtained in each case. Heat resistance is lowest in $10^{\circ}$ acclimation for $5^{\circ}$-and $10^{\circ}$-reared animals and in $20^{\circ}$ acclimation for $20^{\circ}$-and $30^{\circ}$-reared animals. In $30^{\circ}$-reared animals, $5^{\circ}$ acclimation results in a slightly greater resistance than $30^{\circ}$ acclimation. The results disproves the possibility that a change in the environmental temperature alone may induce a gain of heat resistance. Moreover, they show the relations which contradict with the well-established principle of temperature acclimatization that heat resistance is gained much more rapidly on warming than it is lost on cooling.

3. In $20^{\circ}$-reared animals, the lower the acclimation temperature, the higher is the resistance to cyanide when tested at $20^{\circ}$. This suggests that aerobic metabolism is inactivated in acclimation to lower temperatures and activated in acclimation to higher temperatures so that it does not restore readily its original level on returning to $20^{\circ}$. Cyanide resistance somewhat decreases gradually with time in $5^{\circ}$ and $10^{\circ}$ acclimation and increases in $30^{\circ}$ acclimation, conceivably owing to the effect of true temperature acclimatization.

4. Those animals whose respiration has been suppressed for 35 and 59 hours in reduced oxygen concentrations, i.e. $34 \%$ oxygen in $20^{\circ}$ acclimation and $41 \%$ oxygen in $30^{\circ}$ acclimation, prove appreciably increased heat resistance in comparison to those which have been kept in sufficient concentrations of oxygen, i.e. in $93 \%$ oxygen in $20^{\circ}$ acclimation and $99 \%$ oxygen in $30^{\circ}$ acclimation.

5. Heat resistance changes markedly with the salinity of acclimation sea water as well as with the salinity of test sea water. The heat resistance of the control, i.e., $100 \%$ sea water-acclimated animals is highest in $150 \%$ sea water and declines gradually whether the concentration of test sea water is decreased or increased. In $25 \%$ sea water-acclimated animals, heat resistance falls rather rapidly with time and the concentration of test sea water in which they are most resistant to heat moves toward lower concentrations till it reaches $50 \%$ after 48 hours of acclimation. In 150\%-acclimated animals, on the other hand, heat resistance increases significantly till after some 24 hours and the peak appears to be shifted, though slightly, toward higher concentrations.

These relations are considered to be advantageous for Tigriopus to survive elevations of water temperature in summer months which are liable to be accompanied by concentration of sea water due to evaporation.

6. It is inferred from the above results 1-4 that the acquisition of heat resistance in acclimation to temperatures below $20^{\circ}$, i.e. the optimum temperature for the life of Tigriopus, is different in mechanism from that in acclimation to 
higher temperatures. The latter is certainly caused by temperature acclimatization in the strict sense of the term, while the former should be ascribed to the inactivation of aerobic metabolism by cold, which leaves its effect fairly long after temperature is raised.

\section{Acknowledgements}

The writer wishes to express his heartiest thanks to Prof. D. Miyadi of the Kyoto University and Prof. W. OHsAwa of the Osaka City University for valuable criticisms and discussions, to members of the staff of the Seto Marine Biological Laboratory for providing the writer facilities to collect the experimental materials, and to the members of the Adaptive Variation Research Group for encouragements and valuable discussions. He is also indebted to Mr. T. Kimura for photomicrographic illustrations.

\section{REFERENCES}

BeAdle, L. C., and J. B. CRAGG 1940. Studies on adaptation to salinity in Gammarus spp. I. Regulation of blood and tissues and problem of adaptation to fresh water. J. Exp. Biol. vol. 17, pp. 153-163.

BLAžKA, P. 1955. Temperaturadaptation des Gesamtmetabolismus bei der Weinbergschnecke, Helix pomatia L. Zool. Jahrb. (Physiol.) vol. 65, pp. 431-438.

BovbJERg, R. V. 1952. Comparative ecology and physiology of the crayfish Orconectes propinquus and Cambarus fodiens. Physiol. Zool. vol. 25, pp. 34-55.

Brett, J. R. 1944. Some lethal temperature relations of Algonquin Park fishes. Publ. Ont. Fish. Res. Lab. 63 , pp. 549 .

pp. 9-28.

BULlOCK, T. H. 1955. Compensation for temperature in the metabolism and activity of poikilotherms. Biol. Rev. vol. 30, pp. 311-342.

Croghan, P. C. 1958 a. The survival of Artemia salina (L.) in various media. J. Exp. Biol. vol. 35 , pp. $213-218$.

pp. 219-233.

DoudorofF, P. 1942. The resistance and acclimatization of marine fishes to temperature changes. I. Experiments with Girella nigricans (AYRES). Biol. Bull. vol. 83, pp. 219-244.

1945. The resistance and acclimatization of marine fishes to temperature changes.

II. Experiments with Fundulus and Atherinops. Ibid. vol. 88, pp. 194-206.

EKBERG, D. R. 1958. Respiration in tissue of goldfish adapted to high and low temperatures. Biol. Bull. vol. 114, pp. 308-316.

Fisher, K. C. 1958. An approach to the origin and cellular physiology of adaptation to temperature in fish and small mammals. In "Physiological adaptation". pp. 3-48. Ronald Press, New York.

FRY, F. E. J. 1957. The aquatic respiration of fish. In "The physiology of fishes 1", Academic Press, New York.

HART, J. S. 1952. Geographic variations of some physiological and morphological characters in certain freshwater fish. Publ. Ont. Fish. Res. Lab. 72, pp. 1-79.

Hutchinson, R. H. 1913. Some specific. differences among Protozoa with respect to their resistance to heat. J. Exp. Zool. vol. 15, pp. 131-144. 
Hutchinson, R. H. 1915. The effects of certain salts, and of adaptation to high temperatures, on the heat resistance of Paramecium caudatum. J. Exp. Zool. vol. 19, pp. 211-224.

KAnungo, M. S. and C. L. Prosser 1959. Physiological and biochemical adaptation of goldfish to cold and warm temperatures. 1. Standard and active oxygen consumptions of cold- and warm-acclimated goldfish at various temperatures. J. Cell. and Comp. Physiol. vol. 54, pp. 259263.

KINNE, O. 1958. Adaptation to salinity variations-some facts and problems. In "Physiological adaptation", pp. 92-105. Ronald Press, New York.

KIRBERGER, C. 1953. Untersuchungen übere die Temperaturabhängigkeit von Lebensprozessen bei verschiedenen Wirbellosen. Z. vergl. Physiol. Bd. 35, pp. 175-198.

KROG, J. 1954. The influence of seasonal environmental changes upon the metabolism, lethal temperature and rate of heart beat of Gammarus limnaeus (Smith) taken from an Alaskan lake. Biol. Bull. vol. 107, pp. 397-410.

LOEB, J. and H. WASTENEYS 1912. On the adaptation of fish (Fundulus) to higher temperatures. J. Exp. Zool. vol. 12, pp. 543-557.

MARSHALL, S. M. and A. P. ORR 1955. The biology of a marine copepod. Oliver and Boyd, Edinburgh.

MATUTANI, K. 1959. Temperature adaptation in Tigriopus japonicus. Zool Mag. vol. 68, p. 88. 1960 a. Studies on the temperature and salinity resistance of Tigriopus japonicus. I. Changes in heat resistance in relation to acclimation temperatures of Tigriopus japonicus reared at $20^{\circ} \mathrm{C}$. Physiol. and Ecol. vol. 9, pp. 35-38.

$1960 \mathrm{~b}$. Studies on the temperature and salinity resistance of Tigriopus japonicus. II. Changes in heat resistance in relation to acclimation temperatures of Tigriopus japonicus reared at 4 different temperatures. Ibid. vol. 9, pp. 39-43.

OHSAWA, W. and H. TSUKUDA 1956. The seasonal variation in the temperature response relation and temperature tolerance of the periwinkle, Nodilittorina granularis (GRAY). J. Inst. Polytech. Osaka City Univ., Ser. D, vol. 7, pp. 173-188.

PRECHT, H. 1958. Concepts of the temperature adaptation of unchanging reaction systems of cold-blood animals. In "Physiological adaptation", pp. 50-78. Ronald Press, New York.

Prosser, C. L., L. M. BARR, R. D. PINC, and C. Y. LAUER 1957. Acclimation of goldfish to low concentrations of oxygen. Physiol. Zool. vol. 30, pp. 137-141.

RANADE, M. R. 1957. Observations on the resistance of Tigriopus fulvus (Fischer) to changes in temperature and salinity. J. Mar. Biol. Ass. U. K. vol. 36, pp. 115-119.

SAPPER, I. 1935. Versuche zur Hitzeresistenz der Pflanzen. Planta. Bd. 23, pp. 518-556.

SAYLE, M. H. 1928. Factors influencing the rate of metabolism of Aeshna umbrosa nymphs. Biol. Bull. vol. 54, pp. 212-230.

SPOoR, W. A. 1955 . Loss and gain of heat-tolerance by the crayfish. Biol. Bull. vol. 108, pp. 77-87.

SUMNER, F. B. and P. DOUdOROFF 1938. Some experiments upon temperature acclimatization and respiratory metabolism in fishes. Biol. Bull. vol. 74, pp. 403-429.

TAKEDA, N. 1939. Sex determination and sex differentiation in the marine copepod, Tigriopus japonicus MORI. Zool. Mag. vol. 51, pp. 1-13.

1954. Thermal adaptation in the marine copepod, Tigriopus japonicus Mori. Physiol. and Ecol. vol. 6, pp. 49-54.

TokiokA, T. and T. SuzUKr 1939. A glimpse upon the biology of Tigriopus japonicus Mori, a harpacticoid copepod found commonly in tide-pools. Ecol. Rev. vol. 5, pp. 152-159.

TsukudA, H. and W. OHSAWA 1959. Temperature dependence and acclimatization of the rate of heart beat of a red snail, Physa sp. in relation to size. J. Inst. Polytech. Osaka City Univ., Ser. D, vol, 10, pp. 105-113.

TsukudA, H. 1960. Temperature adaptation in fishes. IV. Change in the heat and cold tolerances of the guppy in the process of temperature acclimatization. Ibid. vol. 11, pp. 43-54.

VERṆON, H. M, 1899. J. Physiol. vol. 24, p. 239. Quoted in Heilbrunn, 1952. 


\section{EXPLANATION OF PLATES XVI-XVII}

\section{Plate XVI}

Fig. 1. View of the rocky shore of Sakinoyu, near the Seto Marine Biological Laboratory, where Tigriopus japonicus MORI occurs abundantly.

Fig. 2. Near view of the natural habitat of Tigriopus japonicus MorI, showing two tide pools on the upper rocky shore, where ex- perimental materials were collected.

\section{Plate XVII}

Fig. 3. Adult male of Tigriopus japonicus MoRI.

Fig. 4. Adult female carrying an egg sac.

Fig. 5. Adult male killed by heat.

Fig. 6. Adult female killed by heat. 